\title{
Vivir en Campamentos: ¿Camino hacia la vivienda formal o estrategia de localización para enf rentar la vulnerabilidad?
}

Isabel Brain Valenzuela Centro de Políticas Públicas UC, Santiago Chile. José Joaquín Prieto Suárez Observatorio Social Universidad Alberto Hurtado. Francisco Sabatini Downey Instituto de Estudios Urbanos y Territoriales, Pontificia Universidad Católica de Chile.

RESUMEN | Con base en una encuesta comparativa a asentamientos irregulares y conjuntos de "vivienda social" de la Región Metropolitana de Santiago, caracterizamos la decisión de vivir en estos "campamentos" como orientada a combinar dos objetivos generalmente excluyentes: mejorar la localización dentro de la ciudad y acceder a una vivienda formal en propiedad. El que los campamentos se sigan recreando a pesar de la masiva producción de unidades subsidiadas por el Estado, y el que la mayoría de sus residentes no estén bajo la línea de la pobreza, avalan esta conclusión. Los campamentos no calzan con la idea común de estar formados por grupos de hogares pobres que han ocupado ilegalmente un suelo como única alternativa residencial y como forma de acceder a la "casa propia". Esta realidad, insospechada para muchos, representa un desafío a las actuales políticas habitacionales que tienden a aglomerar la vivienda social en la periferia urbana y a formar vastos distritos urbanos socialmente homogéneos o segregados donde está anidando el fenómeno del gueto.

PALABRAS CLAVE | Campamentos, localización, política habitacional, segregación.

ABSTRACT | Based on a comparative survey of shanty towns and "social housing" complexes in the Metropolitan Region of Santiago, we characterize the decision to live in campamentos (shanty towns) as combining two, usually mutually exclusive, goals: an improvement in location within the city, and access to more formal housing. The fact that campamentos persist in spite of the massive production of state-subsidized dwellings, and that most of their residents are above the poverty line, support this contention. Campamentos do not fit the common idea of groups of poor households who have occupied land illegally as the only residential alternative and as the means of securing ownership of a formal "social housing" unit. This situation, unexpected by many, represents a challenge to current housing policies which tend to agglomerate social housing in the urban periphery, forming vast socially homogeneous or segregated urban districts where a ghetto phenomenon becomes embedded.

KEY WORDS | Slums, location, housing policy, segregation.

Recibido el 4 de octubre de 2010, aprobado el 16 de noviembre de 2010. Correspondencia: Isabel Brain Valenzuela. Fono: 56-2-3545607.E-mail: ibrain@uc.cl.

José Joaquín Prieto Suárez. Fono: 56-2-8897390. E-mail: jjprieto@osuah.cl.

Francisco Sabatini Downey. Fono: 56-2-354 5502. E-mail: fsabatin@uc.cl. 


\section{Introducción}

En estas páginas entregamos los resultados de un estudio sobre las decisiones de localización de los residentes de asentamientos informales, o "campamentos", de la Región Metropolitana de Santiago de Chile (RMS) ${ }^{1}{ }^{2}$. Dichas decisiones -argumentaremos- muestran las limitaciones de los programas de vivienda social basados en la construcción masiva de vivienda en terrenos baratos de la periferia urbana.

Los datos del estudio ponen en duda que la existencia de campamentos sea una clara y simple manifestación del "déficit habitacional". Corresponde también a una decisión calculada de sus residentes para mejorar su localización dentro de la ciudad. El costo es prolongar en el tiempo la condición de informalidad o ilegalidad en la ocupación del suelo. Permanecer en el "campamento" permite mejorar las posibilidades de lograr progresos en lo personal y familiar y, asimismo, mantener la atención de las autoridades sobre su pendiente problema de vivienda.

Vivir en un campamento no va, sin embargo, de la mano con un rechazo a la vivienda social. Por el contrario, en forma mayoritaria los hogares de los asentamientos informales manifiestan una excelente evaluación de la vivienda social. Es, de hecho, su principal alternativa de acceso a una vivienda formal: a una que les provea de un título de propiedad. En efecto, casi la totalidad de los hogares de campamentos que no están postulando actualmente a un subsidio habitacional, señalan que postularán a uno en el futuro.

Lo que los residentes de campamentos rechazan es la experiencia del gueto que les ofrecen los conjuntos de vivienda social. Resulta evidente que el gueto emerge asociado a la formación de macrozonas con elevados niveles de homogeneidad social, conformación espacial que puede atribuirse principalmente a la construcción masiva de dichas viviendas en la periferia.

Analizaremos los factores que afectan la percepción de los habitantes de campamentos respecto a la vivienda social, lo mismo que aquellos que explican sus opciones y preferencias residenciales. Nos ocuparemos también de las historias residenciales de los hogares de campamentos. Ellas nos muestran que este tipo de asentamiento resulta ser bastante dinámico. Permanentemente entran nuevas familias al campamento, mientras otras parten. Ofrece a sus habitantes la posibilidad de localizarse en áreas intraurbanas con una más densa "geografía de oportunidad" (Galster y Killen, 1995), en comparación con los conjuntos típicos de vivienda social.

En lo teórico, nuestra principal conclusión es que los aumentos en la inseguridad económica y la incertidumbre social propios de la época actual vuelven críticas para los grupos vulnerables la localización y las relaciones espaciales dentro de las ciudades. En lo práctico, creemos que se deberá fortalecer el subsidio a la vivienda usada o de segunda mano dentro de la política habitacional chilena. Así las familias

1 Este estudio fue realizado en el marco institucional de ProUrbana del Centro de Políticas Públicas UC y el Observatorio Social de la Universidad Alberto Hurtado. Junto con ello, contó con el apoyo del Lincoln Institute of Land Policy, EE.UU.

2 Agradecemos la colaboración de Martim Smolka, Ciro Biderman y Anna Santana del Lincoln Institute of Land Policy, y de Pía Mora, de ProUrbana del Centro de Políticas Públicas UC. 
tendrían más posibilidad de elegir su lugar de residencia. La importancia de este ámbito de libertad se hace patente al desglosar la historia de cambios de residencia de los hogares que llegan a vivir a un campamento, como veremos.

El terremoto del 27 de febrero que afectó a una vasta región del Centro-Sur de Chile, incluido Santiago, sin duda ha cambiado la situación que analizamos. Podría pensarse que los daños, que se calculan en más de 81.149 viviendas destruidas, 100.247 viviendas con daños mayores y 192.388 viviendas con daños menores en el país $^{3}$, nos retrotrajo a una situación que, en buena medida, dábamos por superada. ¿Debería el "déficit habitacional" ocupar de nuevo el centro de nuestras preocupaciones y el objetivo de mejorar la localización dentro de las ciudades ser postergado?

No cabe duda que ahora faltan más viviendas que antes del terremoto, pero la demanda por localización, lejos de desaparecer, está emergiendo bajo nuevas formas. La destrucción de viviendas antiguas en los distritos centrales pone a sus habitantes, modestos muchos de ellos, en peligro de ser expulsados a la periferia urbana. Por una parte, la brecha entre la renta potencial y efectiva de esos suelos los vuelve atractivos para proyectos inmobiliarios "gentrificadores" y, por otra, no se dispone de una buena capacidad empresarial en el campo de la construcción para responder a la demanda por reconstrucción de viviendas in situ. Las empresas constructoras han ido evolucionando en el país hacia promotoras que rentan con el suelo, por lo que la mera edificación no les resulta atractiva.

La demanda de los grupos vulnerables por mejorar su localización seguirá fuerte mientras el trabajo sea "flexible" y desprotegido, y lo que ha hecho el terremoto es producir una nueva variante de esa demanda: la de quienes no quieren ser expulsados al borde de las ciudades por promotores o gentrificadores que buscarán aprovechar las oportunidades de negocio inmobiliario que el terremoto les abrió en las áreas consolidadas de las ciudades.

\section{Contexto}

Ha sido tradicional que los estudiosos de las ciudades latinoamericanas hayan descrito su crecimiento demográfico y geográfico como un movimiento espacial centrífugo hacia la periferia, en condiciones de baja densidad y con un predominio de familias nuevas de extracción popular. La trayectoria típica seguida por los inmigrantes urbanos ha sido la de alojarse en los barrios más pobres de la ciudad central en una primera etapa, para luego invadir terrenos periféricos, tal como Richard Morse (1971) sintetizaba el resultado de numerosos estudios ${ }^{4}$.

En un primer momento, la ocupación de los tugurios centrales proveía al inmigrante de una accesibilidad que resultaba crítica para que pudiera insertarse en las redes de trabajo, sociales y políticas de la urbe. Posteriormente, con la constitución de una familia y la llegada de los hijos, iría siendo más importante conseguir mayor espacio.

Plan de Reconstrucción Chile Unido Reconstruye Mejor v6 (26.09.10).

4 Entre los autores más destacados que se refieren al crecimiento por etapas en Latinoamérica y al rol que cumplen los barrios centrales y los periféricos en ese marco se cuentan Mangin (1967), Turner (1971), Leeds y Leeds (1967), Cardona (1968) y Roberts (1970). 
En la periferia era posible conseguirlo y, además, lograr el objetivo de la "casa propia" a través de programas de vivienda social, "tomas" de terrenos o loteos ilegales. Todo ello se hacía sacrificando localización, lo que sin embargo era posible porque los hogares habían ido logrando una creciente inserción en las mencionadas redes. Puesto en términos del célebre análisis neoclásico de William Alonso (1964), estos habitantes de bajos ingresos irían sustituyendo accesibilidad por espacio.

Tal movimiento espacial era sustentado por unas condiciones políticas, sociales y económicas, especialmente laborales, que le garantizaban al actor de menores recursos una cierta seguridad o protección. No obstante el lento ritmo de su integración social en comparación con el del crecimiento económico, con el tiempo lograba conocer e insertarse mejor en las redes de la ciudad. Adicionalmente, el asentamiento "marginal" periférico, de gran precariedad inicial, transitaría lentamente a uno relativamente consolidado en lo físico, con implantación mediterránea en la ciudad y de condición social medio-baja. El crecimiento de la ciudad rebasaría e iría absorbiendo a ese primigenio asentamiento informal mientras sus residentes progresarían lenta y trabajosamente en materia de integración social.

Según Enzo Faletto (1964), el migrante no se dirigía a la ciudad para trabajar en la industria sino, más bien y por el contrario, su objetivo principal era vivir en la ciudad siendo secundarios los medios para alcanzar dicho fin. En efecto, el lugar de trabajo no ha sido importante en la localización de la residencia de las clases populares urbanas de América Latina, salvedad hecha del período de llegada del migrante a la ciudad, cuando aún no conocía ni estaba inserto en los circuitos de la economía urbana. Sin embargo, una segunda salvedad la representan los periodos, como el actual, en que el liberalismo económico trae más inseguridad a las familias populares a través de empleos de menor calidad, duración y protección estatal.

En efecto, el modelo centrífugo de crecimiento urbano presenta hoy importantes modificaciones. En las ciudades de América Latina, especialmente en las más grandes, se observa una suerte de "inclinación estructural" de los grupos vulnerables por mejorar su localización dentro de la ciudad. En Buenos Aires, la población en "villas miseria" en el área central de la metrópolis ("Capital Federal” en la terminología local) se duplicó en el último periodo intercensal (1991-2001), mientras la población total de la Capital Federal disminuyó aproximadamente un 8 por ciento. En Río de Janeiro, también en el último periodo intercensal (1991-2001) las favelas que más crecieron demográficamente fueron las mejor localizadas cerca de las playas y de los barrios de ingresos medios y altos, a pesar de que ya eran las más densas y carentes de espacio.

En Chile también se observa esta tendencia, aun cuando el volumen de los asentamientos informales es notablemente más acotado que en el resto de América Latina. Aunque la población chilena residente en asentamientos irregulares representaba en 2007 tan sólo un 0,7 por ciento de la población nacional, los sucesivos "catastros de 
campamentos" muestran que la formación de nuevos campamentos no cesa ${ }^{5}$, y que los campamentos tienden a ubicarse cerca de los lugares de concentración de oportunidades de trabajo y de acceso a servicios, como veremos luego con más detalle.

La persistencia de este número reducido de hogares en campamentos podría atribuirse, primero, a un efecto residual relacionado con el tiempo que inevitablemente transcurre entre la llegada de una familia a un campamento y su erradicación o radicación en una vivienda social formal. Sin embargo, no todos los postulantes al Subsidio Habitacional residen en campamentos, ni siquiera la mayoría de ellos. Es más, vivir en un asentamiento irregular no es requisito para postular a ese subsidio.

Una segunda posibilidad es suponer que los hogares de este tipo forman parte de una lista de espera que será absorbida por los programas de vivienda, y sólo sería cuestión de tiempo para que ello se complete. De hecho, en Chile existe un programa de vivienda especialmente diseñado para atender el déficit de vivienda de las familias de campamentos, originalmente llamado Chile-Barrio y con posterioridad rebautizado como Línea de Atención a Campamentos. Sin embargo, este programa no ha logrado completar la tarea porque sigue entrando gente a los campamentos o se forman nuevos.

La tercera explicación de la persistencia del campamento es que las familias no sólo buscan dejar de vivir como allegados -igual que los miles de postulantes al Subsidio Habitacional que no viven en campamentos-, sino que, además, tienen una preferencia clara por mantenerse en el lugar en que está emplazado su campamento o en las cercanías.

En concreto, la existencia de campamentos no puede ser atribuida a una débil política de regularización ni a la persistencia o aumento de la pobreza. En los últimos veinte años la pobreza ha disminuido a la mitad en Chile, llegando a representar el 13,7 por ciento de los hogares (CASEN, 2006); y en ese mismo período se han entregado subsidios para la compra de viviendas sociales a aproximadamente dos millones de hogares (100 mil hogares en promedio cada año). No sólo se ha cubierto la demanda de vivienda que se genera cada año, sino que se ha reducido a la mitad el déficit habitacional de arrastre.

Sin embargo, políticas de vivienda social de gran cobertura aplicadas por los sucesivos gobiernos han tenido un importante costo: una significativa aglomeración de la vivienda social en la periferia urbana. Precisamente, la persistencia de los campamentos debe entenderse en este contexto. Más y mejores oportunidades son parte de las motivaciones por las cuales muchas familias se mantienen hoy en campamentos, a pesar de las dificultades y problemas que significa vivir en la informalidad y de lo extendido de los programas habitacionales en Chile.

Así como no podemos sentenciar que existen sólo costos o bien sólo beneficios por el hecho de acceder a una vivienda social, tampoco podemos concluir que los campamentos constituyen un tipo de "déficit corriente" de vivienda. Como lo

5 Más de la mitad de los 533 campamentos existentes en Chile el año 2007, que incluían 28.578 hogares y 105.000 personas, se crearon después de 1991 (Fundación Un Techo para Chile (2007)). 
plantea J.C. Skewes: "No todos requieren lo mismo, no todos se benefician de las mismas soluciones. Las villas, por ejemplo, traen aparejadas ventajas incuestionables: agua potable, corriente al interior de la casa, alcantarillado, luz eléctrica. Es difícil que alguien se resistiera a estas comodidades. Sin embargo, una exploración más en detalle sugiere que no todo es como planificadores, residentes y arquitectos quisieran. La villa, que acoge a millares de familias sin casa, tiene sus bemoles, y los predios que atrás se dejaron no eran sólo tierras baldías" (Skewes, 2003).

La importancia que ha cobrado la localización para los grupos populares tuvo una manifestación militante en la declaración entregada a los medios por el $\mathrm{Mo}$ vimiento de Allegados en la Lucha de Peñalolén, comuna popular de la periferia de Santiago, con ocasión de un intento frustrado de "toma" de tierras en esa comuna: "Mientras vemos cómo se construyen las viviendas lujosas y grandes parques para los ricos de la comuna, nosotros nos vemos forzados a migrar hacia la periferia, a lugares donde hoy no hay empleo ni tampoco servicios básicos, como hospitales y colegios" (Diario La Tercera, marzo 13 de 2006). En los últimos dos decenios Peñalolén ha estado sometida a un proceso de "gentrificación", o llegada de grupos de mayores ingresos, que ha contribuido a elevar los precios del suelo y hacer muy difícil la construcción de vivienda social para los hogares nuevos formados en esa comuna.

El aumento de la demanda por mejor localización al interior de la ciudad entre los habitantes urbanos de extracción popular, nos parece una cuestión estructural o de contexto histórico. Basamos esta convicción en tres observaciones. La primera, es que el desarrollo económico actual comprende grados altos de inestabilidad y de precarización del empleo, y de segmentación de la calidad de la oferta educativa y de salud en función a lo que las personas pueden pagar. Una buena localización mejora las oportunidades de trabajo en estos mercados "flexibles". Por una parte, reduce la distancia física a las oportunidades laborales y a los servicios sociales públicos y, por otra, en tanto la buena localización consiste en mayor heterogeneidad social del espacio, contribuye a la circulación de más y mejor información sobre oportunidades de trabajo, a reforzar las redes sociales y a mejorar el acceso al comercio y los servicios privados.

Nuestra segunda observación se refiere a la transformación radical del sistema político que hizo desaparecer la relación orgánica y cotidiana entre partidos y clases populares. El clientelismo, al menos en sus viejas formas, aquellas que permitían argumentar sobre la "centralidad de los marginales" (el título de un trabajo del sociólogo Alain Touraine, 1987) y que mantenían articulados los barrios populares periféricos al sistema político, ha retrocedido significativamente. Lo tercero es que la segregación residencial de los grupos pobres se ha vuelto maligna (Sabatini, Cáceres y Cerda, 2001; Sabatini y Cáceres, 2004). La homogeneidad social del espacio en barrios donde se concentran los hogares vulnerables favorece el desempleo y el crimen, entre muchos otros problemas sociales, como muestra la investigación a nivel internacional y también nacional (Sabatini, Wormald, Sierralta y Peters, 2009). En suma, el barrio importa, y más que antes. Así se puede entender la decisión de los residentes de campamentos de haberse mudado y permanecer allí. 
Sin embargo, si la localización es tan importante, ¿por qué, entonces, apenas un 0,7 por ciento de los hogares de Chile vive en asentamientos informales? Una razón es que hoy es más difícil la ocupación ilegal de tierras o "tomas". El derecho de propiedad está mejor protegido que nunca en Chile, tanto legalmente como en lo policial. A esto se suma una política habitacional que tiene la capacidad de atender en forma bastante rápida y expedita a las familias que postulan a una vivienda social. La política adjudica un subsidio a la demanda, en la forma de un voucher, a las familias que cumplen con ciertos requisitos de ahorro previo y nivel de pobreza. En los meses antes del terremoto recibían el voucher en promedio tres meses después de haber postulado.

Los reparos que estas personas pudieran tener en términos de la implantación segregada de los conjuntos de vivienda social han sido hasta ahora neutralizados por la posibilidad de obtener muy rápido una vivienda formal con título de propiedad, con un ahorro equivalente a tan sólo el tres por ciento de su valor total y que no conlleva el pago de dividendos.

Las familias de campamentos nos muestran, sin embargo, que "el sueño de la casa propia" - una aspiración de muchas clases sociales en Chile-puede ir acompañado de una demanda por localización, por una mejor geografía de oportunidad, demanda que hasta aquí no ha sido importante para las políticas habitacionales.

El voucher que entrega el Estado a las familias para acceder a una vivienda social funciona bajo el supuesto que pueden "elegir" su vivienda y su localización. Sin embargo, este subsidio es incapaz de competir por suelo con hogares mejores pagadores, por lo que finalmente la única opción que han tenido es elegir dentro de la oferta que el sector privado entrega a estas familias: viviendas en complejos habitacionales de gran tamaño ubicados en la periferia de las ciudades, cuyo sello principal es la formación de grandes zonas socialmente homogéneas.

$\mathrm{Al}$ incluir el precio a pagar por el suelo, el Subsidio Habitacional ha favorecido la operación de empresas inmobiliarias que rentan con el suelo. Con el fin de maximizar sus ganancias rentistas, buscan construir en terrenos de valores "rurales". Las licitaciones ganadas por empresas constructoras que construían viviendas sociales en terrenos provistos por las autoridades, son cosa del pasado. Como mecanismo de financiamiento, el Subsidio Habitacional ha contribuido a la aglomeración de conjuntos de viviendas en la periferia homogénea y mal servida, de paso debilitando la soberanía del consumidor al restringir severamente su posibilidad de elección. En este sentido, el Subsidio Habitacional ha sido un subsidio a la oferta más que a la demanda.

Tal como Rodríguez y Sugranys plantean, la política de vivienda es más bien una política de financiamiento de la vivienda. "La discusión se plantea erróneamente cuando se dice que hubo un dilema entre el número y la calidad al decidir las opciones de política habitacional, y que se optó por la cantidad. Se optó, en realidad, por los aspectos de financiamiento. Se dejó de lado el diseño arquitectónico y urbano, lo cual llevó a olvidar el lugar, la localización, el entorno" (Rodríguez, A. et al., 2000). 


\section{RECUADRO METODOLÓGICO 1}

El estudio trabajó con tres muestras de hogares: (i) Residentes en campamentos de la RMS; (ii) Residentes en viviendas sociales en la RMS que antes vivían en campamentos que fueron radicados o erradicados, y (iii) Residentes en viviendas sociales de la RMS que no provienen de campamentos. Los tamaños de las muestras fueron de 812, 510 y 266 hogares, respectivamente. Las encuestas fueron aplicadas presencialmente en agosto de 2009 para los hogares de campamentos y en diciembre de 2009 para los hogares de viviendas sociales. Los entrevistados fueron jefes de hogar o cónyuges.

VAlORES DE SUELO (USD/M² POR ZCS)

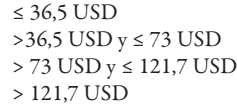

Para la muestra de campamentos, el marco muestral fue el catastro de campamentos 2007 de la Fundación Un Techo para Chile. En una primera etapa se estratificó por precio de suelo y tamaño del campamento, y se seleccionaron aleatoriamente campamentos que fueron empadronados para realizar, en una segunda etapa, una selección aleatoria de hogares dentro de cada uno de éstos. La estratificación por precio de suelo recurrió, como referencia, a los valores de tasación de las zonas de características similares (ZCS) más altos de cada comuna. Las ZCS corresponden a una segmentación que realiza el Servicio de Impuesto Internos (SII) según usos predominantes del suelo y sectores de cada comuna. Los valores de suelo utilizados se presentan en el siguiente Cuadro:

\begin{tabular}{rcc} 
Hogares & Tamaño Muestral & Error Muestral \\
\hline Asentamientos & 812 & $0,06 \%$ \\
informales & 510 & $0,10 \%$ \\
Vivienda Social (1) & 266 & $0,18 \%$ \\
Vivienda Social (2) & 1.588 &
\end{tabular}

Dada esta tendencia de una economía urbana cada vez más dominada por la lógica del promotor inmobiliario, emerge la localización como un objetivo importante para los grupos vulnerables. Y el residir en un campamento es una forma concreta de elevar la probabilidad de obtener una vivienda social en el mismo sector o comuna en la que viven, de evitar la resegregación hacia la periferia.

El objetivo de mejorar su localización no es privativo de los residentes de campamentos. Es también la de otros grupos vulnerables, como los inmigrantes peruanos que llegan a Santiago buscando trabajo. Se instalan en el área central, donde las redes de contacto y oportunidades de empleo son más extensas o, en el caso de las mujeres que trabajan como asesoras del hogar, en el sector Oriente de ingresos altos. En cambio, los hogares Mapuche -la principal etnia indígena de Chile que, al igual que los peruanos, llegan al área central de la ciudad- por ser sujetos de derechos y garantías sociales acceden a los subsidios habitacionales en conjuntos de la periferia urbana. 
FIGURA 1 | Concentración de hogares peruanos y mapuche en la ciudad de Santiago, según el Censo de 2002

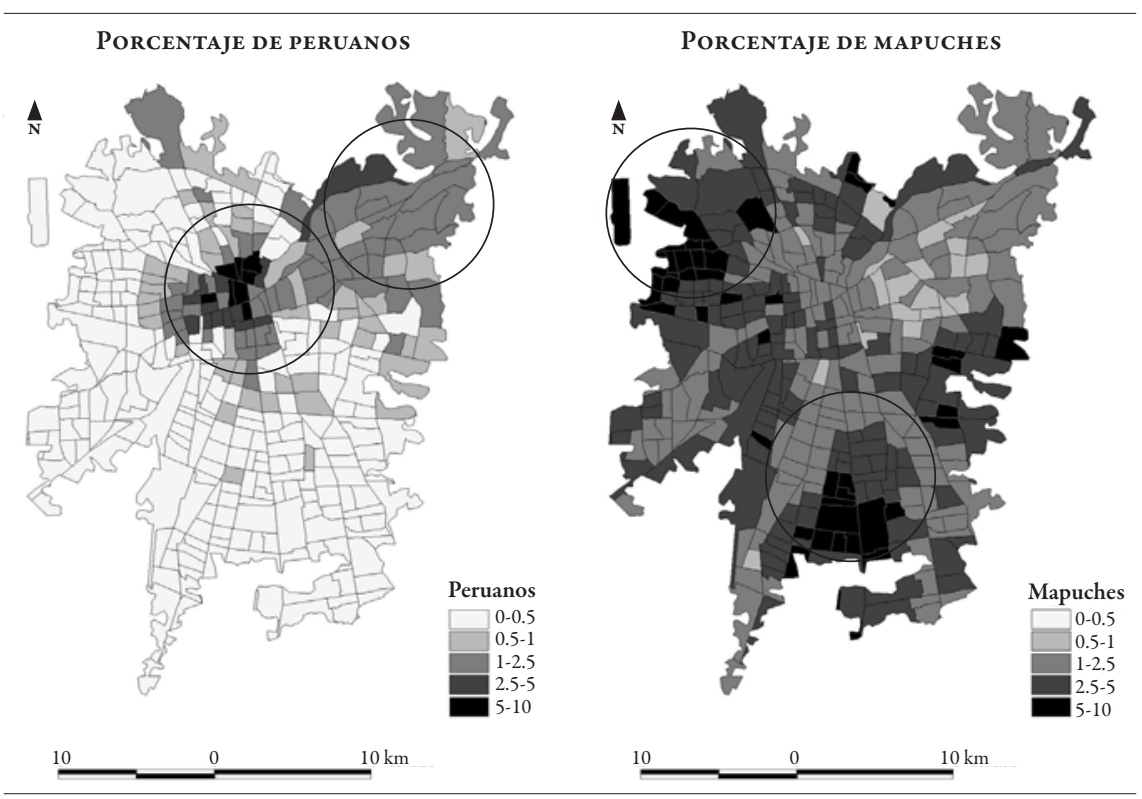

FUENTE ELABORACIÓN PROPIA.

1 Vivir en un campamento es una estrategia para ejercer preferencias de vivienda y de localización

Un porcentaje importante de los hogares que antes vivían en campamentos y que hoy viven en viviendas sociales permanecieron en la misma comuna. Sin modificar mayormente su localización, a través del Subsidio Habitacional lograron acceder a mejores estándares de habitabilidad y a un título de propiedad. En efecto, siete de cada diez hogares de campamentos que hoy habitan en vivienda social se mantuvieron en su misma comuna, en contraste con sólo algo más de la mitad de los que no provenían de campamentos (Cuadro 1) ${ }^{6}$.

CUADRO 1 | RMS 2008: procedencia de los hogares de asentamientos informales y de viviendas sociales

\begin{tabular}{rccc}
\hline & $\begin{array}{c}\text { Asentamiento } \\
\text { Informal }\end{array}$ & $\begin{array}{c}\text { Vivienda } \\
\text { Social (1) }\end{array}$ & $\begin{array}{c}\text { Vivienda } \\
\text { Social (2) }\end{array}$ \\
\hline Otra Región & $6,3 \%$ & $2,4 \%$ & $2,7 \%$ \\
RM (otra COMUna) & $33,0 \%$ & $28,1 \%$ & $45,6 \%$ \\
RM (Misma COMUna) & $60,7 \%$ & $69,5 \%$ & $51,7 \%$ \\
\hline
\end{tabular}

(1) Proviene de asentamiento informal

(2) No proviene de asentamiento informal

FUENTE ELABORACIÓN PROPIA A PARTIR DE BASE DE DATOS ESTUDIO SOBRE CAMPAMENTOS Y VIVIENDA SOCIAL REALIZADO POR PROURBANA, CENTRO POLÍTICAS PÚBLICAS UC Y OBSERVATORIO SOCIAL, UAH, 2009.

6 Según estimaciones del Instituto Nacional de Estadísticas de Chile, el año 2007 la RMS tenía 6.490.248 habitantes y 52 municipios. El tamaño promedio de los municipios era de 125.000 habitantes, aproximadamente. 
En lo relativo a percepciones, un 63 por ciento de los hogares de campamentos considera que su lugar de residencia les reporta ventajas para acceder a una vivienda social en comparación con otras familias. La realidad confirma su opinión: entre 1996 y 2007 los campamentos se redujeron de 972 (con 105.888 hogares) a 490 campamentos (con 20.599 hogares). Esta reducción del número de campamentos de un 50 por ciento y de hogares en campamentos de un 80 por ciento, se explica por el hecho que ha existido un programa especialmente diseñado para terminar con los campamentos en Chile -la Línea de Atención a Campamentos, mencionado antes- que tiene como criterio explícito tratar de evitar el desarraigo de las familias del lugar en que residen.

Al estudiar la historia residencial del tercio de hogares de campamentos que cambiaron de comuna cuando llegaron al campamento, encontramos que un 73 por ciento mantuvo o bien mejoró su localización - al considerar los precios de suelo de las comunas de residencia (ver Cuadro 2).

CUADRO 2 | RMS 2008: hogares de asentamientos informales y de viviendas sociales según comparación entre los precios del suelo en la comuna actual y la anterior

\begin{tabular}{rccc}
\hline $\begin{array}{r}\text { Precio de } \\
\text { Suelo ACtual }\end{array}$ & Asentamiento Informal & Vivienda Social (1) & Vivienda Social (2) \\
\hline Mayor & $32,7 \%$ & $8,4 \%$ & $33,0 \%$ \\
Se mantiene & $40,4 \%$ & $63,0 \%$ & $30,4 \%$ \\
Menor & $26,9 \%$ & $28,7 \%$ & $36,6 \%$ \\
\hline No Muestral & 263 & 140 & 120 \\
\hline
\end{tabular}

(1) Proviene de asentamiento informal

(2) No proviene de asentamiento informal

FUENTE ELABORACIÓN PROPIA A PARTIR DE BASE DE DATOS ESTUDIO SOBRE CAMPAMENTOS Y VIVIENDA SOCIAL REALIZADO POR PROURBANA, CENTRO POLÍTICAS PÚBLICAS UC Y OBSERVATORIO SOCIAL, UAH, 2009.

Cuando las familias "toman" (ocupan ilegalmente) un terreno o cuando deciden vivir en un asentamiento informal que ya existe, ya están ejerciendo su preferencia de localización. En forma consistente, una gran mayoría prefiere que la vivienda social a la que postulan se localice en el mismo sitio o comuna en que residen. Buscan permanecer en la misma comuna, o bien, cambiarse a otra comuna con valores de suelo más altos. Sus preferencias de localización se vuelven claras y gravitantes por la mayor capacidad de presión política que les da el residir en campamentos. En último término, la persistencia de los campamentos delata la insuficiencia de las políticas de vivienda social.

Así, la prioridad que tiene la localización para los grupos vulnerables permite explicar que continúen ingresando familias a vivir en campamentos. Según datos de nuestra encuesta a campamentos, el 61 por ciento de los hogares que residían en campamentos de la RMS el año 2008 habían ingresado entre los años 2000 y 2008 (Cuadro 3). 
CUADRO 3 | RMS 2008: distribución de los hogares de asentamientos informales por período de ingreso

\begin{tabular}{|c|c|c|}
\hline & \multicolumn{2}{|c|}{ ASENTAMIENTO INFORMAL } \\
\hline & No Muestral & $\%$ \\
\hline $2000-2008$ & 463 & 60,6 \\
\hline 1990-1999 & 202 & 23,1 \\
\hline Antes de 1990 & 147 & 16,2 \\
\hline Total & 812 & 100 \\
\hline
\end{tabular}

FUENTE ELABORACIÓN PROPIA A PARTIR DE BASE DE DATOS ESTUDIO SOBRE CAMPAMENTOS Y VIVIENDA SOCIAL REALIZADO POR PROURBANA, CENTRO POLÍTICAS PÚBLICAS UC Y OBSERVATORIO SOCIAL, UAH, 2009.

No debemos perder de vista que la proporción de hogares en vivienda social que proviene de campamentos es una minoría - un 2,2 por ciento el año 2001 (INVI, 2001). Pero es una minoría que "corre con ventaja" respecto de la situación del resto de hogares de extracción popular que han accedido masivamente a los conjuntos de vivienda social en los últimos veinte años.

\section{La extrema pobreza no es lo que mejor define a los hogares de campamentos}

Un 51 por ciento de los hogares de campamentos no se encuentran en situación de pobreza -concluimos al usar la misma metodología de la encuesta de Caracterización Socioeconómica Nacional de hogares, CASEN, que aplica el gobierno de Chile.

Al compararlos con los hogares en situación de pobreza de la encuesta CASEN, los de nuestra muestra de campamentos se revelan como menos vulnerables. Presentan mayores niveles de jefatura masculina, un número menor de integrantes por hogar, e ingresos per cápita que, incluso, duplican los niveles de ingreso de los hogares pobres de la RMS. La creencia tradicional de que en los campamentos habitan las familias más pobres de la sociedad queda, por lo mismo, sin sustento.

La importancia que tiene la geografía de oportunidad en la evolución de los campamentos de la RMS queda demostrada por la diferencia de los índices de pobreza según el emplazamiento específico de los campamentos. Mientras los de comunas con precios de suelo bajo y alto (los extremos) presentan niveles de pobreza de 41 y un 37 por ciento, respectivamente, los localizados en comunas con precios de suelo intermedios exhiben niveles de pobreza significativamente mayores (Cuadro 4).

Considerando que la cobertura de servicios públicos como educación y salud es cercana al 100 por ciento, la geografía de oportunidad está determinada principalmente por la cercanía a las fuentes de trabajo. Los hogares en campamentos periféricos de la RMS (precios de suelo menores) se benefician de una demanda por trabajadores agrícolas; y los campamentos en las comunas de más altos precios del suelo, de las oportunidades laborales de la economía urbana. En comparación, los campamentos de zonas urbanas segregadas y socialmente homogéneas (precios de suelo intermedios) carecen de fuentes laborales cercanas y de servicios de calidad.

En efecto, como muestra el Cuadro 4, los hogares localizados en las comunas de precios de suelo extremos tienen mayores ingresos y una proporción mayor de traba- 
jadores en el sector privado y en el servicio doméstico puertas fuera, en comparación con los hogares localizados en suelo de valor medio.

CUADRO 4 | RMS 2008: características socioeconómicas de los jefes de hogar de campamentos, según localización (en porcentajes sobre el total de hogares de cada campamento)

\begin{tabular}{rcccc}
\hline & \multicolumn{4}{c}{ Precio De SUElo } \\
\cline { 2 - 5 } VARIables & BAJO & Medio BAJo & Medio Alto & Alto \\
\hline Empleado & $57,8 \%$ & $53,5 \%$ & $53,7 \%$ & $63,5 \%$ \\
Ocupación permanente & $68,5 \%$ & $73,2 \%$ & $72,8 \%$ & $85,4 \%$ \\
No tiene contrato & $34,6 \%$ & $35,3 \%$ & $35,6 \%$ & $21,7 \%$ \\
Trabajador por cuenta propia & $14,0 \%$ & $25,6 \%$ & $34,2 \%$ & $17,7 \%$ \\
Empleado u obrero del sector privado & $72,8 \%$ & $66,7 \%$ & $56,3 \%$ & $68,4 \%$ \\
Servicio doméstico puerta afuera & $9,4 \%$ & $4,4 \%$ & $5,9 \%$ & $10,1 \%$ \\
Ingreso per cápita ajustado a 2006 & $\$ 65.660$ & $\$ 52.167$ & $\$ 43.006$ & $\$ 71.193$ \\
Porcentaje pobres & $41,4 \%$ & $56,1 \%$ & $66,4 \%$ & $36,8 \%$ \\
\hline
\end{tabular}

FUENTE ELABORACIÓN PROPIA A PARTIR DE BASE DE DATOS ESTUDIO SOBRE CAMPAMENTOS Y VIVIENDA SOCIAL REALIZADO POR PROURBANA, CENTRO POLÍTICAS PÚBLICAS UC Y OBSERVATORIO SOCIAL, UAH, 2009.

\section{Los campamentos están mejor localizados que la vivienda social}

Los campamentos se hallan principalmente en comunas con valores de suelo más altos que las viviendas sociales. Un 27 por ciento de los campamentos están ubicados en comunas con precio de suelo alto, contra sólo un 8 por ciento de las viviendas sociales (Cuadro 5).

CUADRO 5 | RMS 2008: distribución de los hogares de asentamientos informales y vivienda social según precio del suelo (en porcentajes de hogares)

\begin{tabular}{|c|c|c|}
\hline Precio de Suelo & ASENTAMIENTO INFORMAL & Vivienda Social \\
\hline Bajo & 21,8 & 16,0 \\
\hline Medio Bajo & 27,0 & 46,8 \\
\hline Medio Alto & 24,3 & 29,4 \\
\hline \multirow[t]{2}{*}{ Alto } & 27,0 & 7,9 \\
\hline & $100 \%$ & $100 \%$ \\
\hline Precio de Suelo & ASENTAMIENTO INFORMAL & VIVIENdA Social \\
\hline Bajo & 32,5 & 46,4 \\
\hline Medio Alto & 38,3 & 38,0 \\
\hline \multirow[t]{2}{*}{ Alto } & 29,2 & 15,6 \\
\hline & $100 \%$ & $100 \%$ \\
\hline Precio de Suelo & ASENTAMIENTO INFORMAL & Vivienda Social \\
\hline Bajo & 46,3 & 62,8 \\
\hline Alto & 53,7 & 37,2 \\
\hline & $100 \%$ & $100 \%$ \\
\hline
\end{tabular}

FUENTE ELABORACIÓN PROPIA A PARTIR DE BASE DE DATOS ESTUDIO SOBRE CAMPAMENTOS Y VIVIENDA SOCIAL REALIZADO POR PROURBANA, CENTRO POLÍTICAS PÚBLICAS UC Y OBSERVATORIO SOCIAL, UAH, 2009.

Por otra parte, la percepción de los hogares de campamentos respecto a la cercanía de los servicios y del trabajo es sustantivamente mejor que la percepción que muestran los hogares que residen en viviendas sociales (Cuadro 6). 
CUADRO 6 | RMS 2008: ventajas de localización percibidas por hogares de asentamientos informales y de viviendas sociales

\begin{tabular}{lcc}
\hline $\begin{array}{l}\text { Porcentaje QUe Percibe QUe SE } \\
\text { ENCUentra Cercano A: }\end{array}$ & Asentamiento INFormal & Vivienda Social \\
\hline Escuela o Jardín Hijo Menor & $72,0 \%$ & $67,4 \%$ \\
Supermercado o centro comercial que más frecuenta & $64,7 \%$ & $52,7 \%$ \\
Transporte Público & $84,2 \%$ & $85,8 \%$ \\
Familiar que usted más visita & $71,9 \%$ & $61,3 \%$ \\
Lugar donde trabaja el jefe de hogar & $57,6 \%$ & $39,9 \%$ \\
Lugar donde trabaja el cónyuge/ pareja & $63,1 \%$ & $42,8 \%$ \\
\hline
\end{tabular}

*Tabla respuestas múltiples

FUENTE ELABORACIÓN PROPIA A PARTIR DE BASE DE DATOS ESTUDIO SOBRE CAMPAMENTOS Y VIVIENDA SOCIAL REALIZADO POR PROURBANA, CENTRO POLÍTICAS PÚBLICAS UC Y OBSERVATORIO SOCIAL, UAH, 2009.

Lo mismo ocurre con la percepción de cuán diversa socialmente (poco segregada) es la comuna en la que residen. Se les formularon a cada entrevistado las siguientes dos preguntas: (i) "En una escala de 1 a 10, donde 1 corresponde a las familias con menos dinero y 10 a las familias más ricas, ¿en qué número piensa que está usted?, y (ii) ¿En qué número piensa que están la mayoría de las familias de su comuna?” Mientras los hogares de campamentos se autoclasificaron, en promedio, en el lugar 3 y percibieron que las familias de su comuna se ubican en 5 , los de vivienda social se autoclasificaron en el lugar 3,5 y a las familias de su comuna en el lugar 4,2.

$\mathrm{Si}$, por otra parte, se analiza cómo varía la percepción de cercanía a la geografía de oportunidad según precios de suelo, se aprecia el peso que las personas de extracción popular atribuyen a la localización para mejorar su geografía de oportunidad. En este sentido, los campamentos en suelos cuyo valor es alto muestran ventajas significativas en relación a aquellos que se localizan en comunas con bajo precio de suelo, especialmente en lo que se refiere a distancia al trabajo del jefe de hogar y del cónyuge (Cuadro 7). Es interesante constatar que estas percepciones no registran los mejores resultados en pobreza e ingresos que objetivamente tienen los residentes de campamentos más periféricos, tal vez por su acceso al trabajo rural (Cuadro 4).

CUADRO 7 | RMS 2008: ventajas de localización percibidas por hogares de asentamientos informales según precios de suelo de sus comunas de implantación

\begin{tabular}{lcccc}
\hline $\begin{array}{l}\text { Porcentaje QUE PERCibe QUE SE } \\
\text { ENCUENTRA CERCANO A: }\end{array}$ & BAJO & Medio BAJO & Medio Alto & Alto \\
\hline Escuela o Jardín Hijo Menor & $66,6 \%$ & $66,9 \%$ & $75,8 \%$ & $76,9 \%$ \\
Supermercado o centro comercial que más frecuenta & $49,4 \%$ & $56,7 \%$ & $68,4 \%$ & $81,2 \%$ \\
Transporte Público & $88,9 \%$ & $71,3 \%$ & $88,7 \%$ & $88,3 \%$ \\
Familiar que usted más visita & $73,5 \%$ & $67,9 \%$ & $67,1 \%$ & $77,3 \%$ \\
Lugar donde trabaja el jefe de hogar & $45,8 \%$ & $58,5 \%$ & $53,5 \%$ & $67,5 \%$ \\
Lugar donde trabaja el cónyuge/ pareja & $51,5 \%$ & $61,4 \%$ & $59,3 \%$ & $72,9 \%$ \\
\hline${ }^{*}$ Tabla respuestas múltiples & & & \\
\hline
\end{tabular}

FUENTE ELABORACIÓN PROPIA A PARTIR DE BASE DE DATOS ESTUDIO SOBRE CAMPAMENTOS Y VIVIENDA SOCIAL REALIZADO POR PROURBANA, CENTRO POLÍTICAS PÚBLICAS UC Y OBSERVATORIO SOCIAL, UAH, 2009. 


\section{Los hogares de campamentos valoran su localización}

Frente a la pregunta "Si usted tuviera la oportunidad de cambiarse a otra vivienda, ¿qué elegiría?", un 87 por ciento de los hogares de campamentos de la RMS declaró que preferiría quedarse en la misma comuna, 29 por ciento en el mismo sitio de su campamento y 58 por ciento en otro sitio de la misma comuna.

En términos de expectativas, los residentes de campamentos se proyectan habitando en cinco años más en una vivienda social. Un 67 por ciento cree que será en la misma comuna, y cerca de un 25 por ciento piensa que estará viviendo en una vivienda social en el mismo campamento.

Por último, tal vez el dato más radical sea que un 52 por ciento de los hogares preferiría quedarse en el campamento y en las mismas condiciones habitacionales actuales, antes que irse a una vivienda social lejos de la comuna en la que reside actualmente.

Este interés por mantener su localización se expresa en la disposición que tiene el 59 por ciento de los hogares de ahorrar más dinero que lo que el Estado les exige (400 dólares a los hogares más pobres, aproximadamente) con tal de permanecer en el mismo lugar.

\section{RECUADRO METODOLÓGICO 2}

Para obtener las preferencias de los hogares por localización, se ideó un juego que consiste en que las familias deben optar entre una mejor localización y un sitio de mayor tamaño en dos escenarios distintos.

El escenario 1 consiste en una ciudad hipotética que es monocéntrica y que reúne en el Centro todos los servicios, equipamientos y fuentes de trabajo. Los entrevistados deben elegir entre vivir cerca del Centro en una vivienda con un terreno pequeño, o lejos del Centro en una vivienda con un sitio más grande.

El escenario 2 corresponde a un mapa de la RMS que diferencia las comunas según tramos de precios de suelo. En ese caso los entrevistados deben optar entre vivir en comunas con valores altos del suelo en viviendas con sitios pequeños, o en comunas con valores bajos del suelo en viviendas con sitios más grandes.

Como los hogares de campamentos no son propietarios ni arrendatarios formales de las viviendas o del sitio en que habitan, no es posible modelar su función de preferencias habitacionales por medio de precios observados en el mercado. Además, la vivienda social, que es la alternativa residencial a la cual ellos aspiran, requiere únicamente que las familias entreguen un ahorro mínimo y el resto lo cubre el Estado por medio de un subsidio (voucher). Por lo tanto, sólo es posible intentar construir un set de preguntas que permita revelar sus preferencias de localización.

Las preferencias registradas frente a los escenarios 1 y 2 reafirman la opción de localización que estos hogares hicieron al momento de irse a vivir a un campamento. En efecto, los hogares localizados en comunas con precios de suelo altos, tanto en la ciudad hipotética como en el mapa de comunas de la RMS, son los que han privilegiado la localización por sobre el tamaño de sitio. Quienes tienen una mejor localización la siguen valorando. 
CUADRO 8 | RMS 2008: preferencia entre mejor localización y mayor espacio de los residentes de campamentos en una ciudad monocéntrica hipotética, según precios de suelo de la comuna de residencia actual

\begin{tabular}{lcc}
\hline Precio de Suelo & $\begin{array}{c}\text { Alternativa 1: Privilegia } \\
\text { localización }\end{array}$ & $\begin{array}{c}\text { Alternativa 4: Privilegia } \\
\text { Tamaño sitio }\end{array}$ \\
\hline Bajo & $12 \%$ & $24 \%$ \\
Medio Bajo & $19 \%$ & $21 \%$ \\
Medio Alto & $17 \%$ & $23 \%$ \\
Alto & $52 \%$ & $31 \%$ \\
\hline
\end{tabular}

FUENTE ELABORACIÓN PROPIA A PARTIR DE BASE DE DATOS ESTUDIO SOBRE CAMPAMENTOS Y VIVIENDA SOCIAL REALIZADO POR PROURBANA, CENTRO POLÍTICAS PÚBLICAS UC Y OBSERVATORIO SOCIAL, UAH, 2009.

CUADRO 9 | RMS 2008: preferencia entre mejor localización y mayor espacio de los residentes de campamentos en mapa de comunas de la RMS, según precios de suelo de la comuna de residencia actual

\begin{tabular}{lcc}
\hline Precio de Suelo & $\begin{array}{c}\text { Alternativa 1: Privilegia } \\
\text { Localización }\end{array}$ & $\begin{array}{c}\text { Alternativa 4: Privilegia } \\
\text { Tamaño sitio }\end{array}$ \\
\hline Bajo & $8 \%$ & $41 \%$ \\
Medio Bajo & $5 \%$ & $17 \%$ \\
Medio Alto & $8 \%$ & $24 \%$ \\
Alto & $79 \%$ & $17 \%$ \\
\hline
\end{tabular}

FUENTE ELABORACIÓN PROPIA A PARTIR DE BASE DE DATOS ESTUDIO SOBRE CAMPAMENTOS Y VIVIENDA SOCIAL REALIZADO POR PROURBANA, CENTRO POLÍTICAS PÚBLICAS UC Y OBSERVATORIO SOCIAL, UAH, 2009.

\section{La vivienda social es una buena vivienda, no tanto así sus barrios}

Los residentes de campamentos, lo mismo que quienes se trasladaron de un campamento a una vivienda social, tienen una buena percepción de esta última (Cuadro 10).

De hecho, como vimos antes, dos tercios de los residentes en campamentos (67 por ciento) piensa que en los próximos cinco años estará viviendo en una vivienda social localizada en el mismo sitio, sector o comuna en que habita actualmente. Además, el 61 por ciento de ellos tiene algún familiar o amigo que reside en una vivienda social, por lo que conocen esta alternativa, y una amplia mayoría (89 por ciento) está postulando o quiere postular a un subsidio de vivienda.

Los actuales residentes de campamentos son más críticos de la vivienda social en comparación con los que residen en viviendas sociales y provienen de campamentos. Es probable que en ello influya el éxito del segundo grupo en haber logrado ejercer su preferencia de localización, ya que gran parte de ellos permaneció en su comuna al salir del campamento. Lo peor evaluado es el tamaño de la vivienda social por los actuales residentes de campamentos.

Por otra parte, resalta cuánto baja la aprobación de la vivienda social en ambos grupos cuando se evalúa la seguridad y el nivel social del barrio. Es una preferencia concordante con la identificación de los problemas de delincuencia, drogadicción y narcotráfico como los peores de los lugares en que se localiza su vivienda. 
CUADRO 10 | RMS 2008: evaluación de los atributos de la vivienda social, según lugar de residencia actual

\begin{tabular}{|c|c|c|}
\hline \multirow{2}{*}{$\begin{array}{l}\text { EVALUACIÓN DE LOS ATRIBUTOS DE LAS VIVIENDAS BÁSICAS QUE } \\
\text { ENTREGA EL ESTADO A LAS FAMILIAS MÁS POBRES }\end{array}$} & \multicolumn{2}{|c|}{$\begin{array}{c}\text { PorCentaje QUE RESPONDIÓ "BUENo" } \\
\text { Y "ACEPTABLE" }\end{array}$} \\
\hline & $\begin{array}{l}\text { ASENTAMIENTO } \\
\text { INFORMAL }\end{array}$ & $\begin{array}{l}\text { VIVIENDA } \\
\text { SOCIAL }(1)\end{array}$ \\
\hline Las viviendas básicas en general & 70,9 & 90,9 \\
\hline La calidad de la construcción & 62,9 & 88,9 \\
\hline La ubicación & 61,8 & 79,4 \\
\hline El tamaño & 40,6 & 67,9 \\
\hline La seguridad en las villas de viviendas básicas & 52,8 & 55,5 \\
\hline La calidad de las plazas, calles, iluminación, etc. & 64,6 & 76,0 \\
\hline La cercanía a los centros de salud, educación, supermercados, centros comerciales, etc. & 67,4 & 86,2 \\
\hline El nivel social del barrio y de las familias que viven en las viviendas básicas & 56,1 & 61,8 \\
\hline \multicolumn{3}{|l|}{ * Tabla de Respuestas Múltiples } \\
\hline \multicolumn{3}{|l|}{${ }^{* *}$ Las categorías de respuesta en esta pregunta eran bueno, aceptable y malo } \\
\hline (1) Proviene de asentamiento informal & & \\
\hline
\end{tabular}

FUENTE ELABORACIÓN PROPIA A PARTIR DE BASE DE DATOS ESTUDIO SOBRE CAMPAMENTOS Y VIVIENDA SOCIAL REALIZADO POR PROURBANA, CENTRO POLÍTICAS PÚBLICAS UC Y OBSERVATORIO SOCIAL, UAH, 2009.

Las respuestas de los habitantes de campamentos a la pregunta “Pensando en su actual vivienda y barrio, qué es lo que a su juicio más le agrega valor a su vivienda?”, se concentraron principalmente en la tranquilidad, seguridad y baja delincuencia que hay en el campamento ( 24 por ciento) y en las características de la comuna como "buena comuna, buen ambiente, buena ubicación" (22 por ciento). En el caso de las familias en vivienda social, el 32 por ciento considera que ese atributo es el que le agrega más valor a su vivienda, junto con las características de la vivienda y sitio en que habitan (24 por ciento).

En cuanto a las respuestas a la pregunta " $¿$ Pensando en su actual vivienda y barrio, qué es lo que a su juicio más le quita valor a su vivienda?”, tanto para los hogares de campamentos como para los de vivienda social son los problemas de delincuencia, droga, alcoholismo y vagancia los que más restan valor a su vivienda. Sin embargo, la magnitud del problema parece ser muy distinta, puesto que sólo un 20 por ciento de los hogares de campamentos menciona estos problemas en comparación con el 46 por ciento de las familias de vivienda social. Dentro de estas últimas, se observa una diferencia importante según la tipología de la vivienda; quienes habitan en departamentos identifican estos problemas en un 56 por ciento, mientras quienes habitan en casa lo hacen en un 44 por ciento.

\section{Razones de peso para no mudarse a una vivienda social son su mala calidad y la inseguridad y bajo nivel social de sus barrios}

El 91 por ciento de quienes viven en campamentos señalan una baja calidad de construcción como el factor principal para desistir de irse a una vivienda social. En definitiva, la precariedad material de sus actuales viviendas de campamento es un problema cotidiano para ellos. En segundo lugar, ocho de cada diez familias rechazarían la vivienda social si el barrio fuera más inseguro que el campamento. Por 
último, un 76 por ciento no se iría a una vivienda social si el nivel social del barrio y de las familias fuera peor que el actual.

CUADRO 11 | RMS 2008: condiciones bajo las cuales las familias de asentamientos informales rechazarían irse a una vivienda social

\begin{tabular}{lc}
\hline ¿RECHAZARía O NO RECHAZARía IRSE A UNA & \% \\
VIVIENDA SOCiAL SI...? & "Sí RECHAZARÍA" \\
\hline Si los gastos en la nueva casa fueran muy caros para el presupuesto familiar? & 45,9 \\
Si la vivienda quedara muy lejos de sus familiares y amigos? & 25,4 \\
Si la vivienda quedara muy lejos de donde Ud. o su pareja trabajan? & 36,7 \\
Si la vivienda fuera muy pequeña para su familia? & 53,9 \\
Si el barrio fuera más inseguro que el lugar en que Ud. vive ahora? & 80,6 \\
Si la calidad de construcción de la vivienda fuera mala? & 91,4 \\
Si el nivel social del barrio y de sus familias fuera peor que el del lugar en el que Ud. vive ahora? & 76,0 \\
Si quedara muy lejos del colegio de su hijo menor? & 34,3 \\
\hline * Tabla de respuestas múltiples &
\end{tabular}

FUENTE ELABORACIÓN PROPIA A PARTIR DE BASE DE DATOS ESTUDIO SOBRE CAMPAMENTOS Y VIVIENDA SOCIAL REALIZADO POR PROURBANA, CENTRO POLÍTICAS PÚBLICAS UC Y OBSERVATORIO SOCIAL, UAH, 2009.

Las familias rechazan aspectos asociados a condiciones del entorno de la vivienda, mientras que los inconvenientes relacionados con una peor localización se mencionan menos. Como vimos, la gran mayoría piensa que accederá a una vivienda social en su misma comuna, lo que podría explicar que la distancia al colegio o al trabajo haya recibido menos atención.

\section{No pocos se arrepienten de haber dejado su campamento}

Aun cuando el nivel de satisfacción respecto a la vivienda social es alto, llama la atención que un 28 por ciento de nuestros entrevistados que hoy habitan una y que provienen de un campamento declaren que se encuentran arrepentidos de haber dejado el campamento.

Cuadro 12 | RMS 2008: ¿̨se arrepiente de haber dejado el campamento? (aplicado a hogares residentes en vivienda social y que provienen de campamento)

\begin{tabular}{lc}
\hline ¿SE ARREPIENTE DE hABER DEJADO EL CAMPAMENTO ? & $\%$ \\
\hline Sí & $\mathbf{2 8 , 2}$ \\
$\mathrm{No}$ & 70,3 \\
$\mathrm{~N} s / \mathrm{Nr}$ & 1,5 \\
Total & $\mathbf{1 0 0 , 0}$ \\
\hline
\end{tabular}

${ }^{*}$ Familias de vivienda social que proviene de campamento

FUENTE ELABORACIÓN PROPIA A PARTIR DE BASE DE DATOS ESTUDIO SOBRE CAMPAMENTOS Y VIVIENDA SOCIAL REALIZADO POR PROURBANA, CENTRO POLÍTICAS PÚBLICAS UC Y OBSERVATORIO SOCIAL, UAH, 2009.

Nuevamente, los motivos de la insatisfacción se relacionan con aspectos "contextuales" del barrio y sector en el cual se emplazan las viviendas. 
CUADRO 13 | RMS 2008: razones por las cuales se arrepiente de haber dejado el campamento

\begin{tabular}{lc}
\hline ¿POR QUÉ SE ARREPIENTE DE HABERLO DEJADO & $\%$ \\
\hline Era más tranquilo, mejor barrio, mejor ambiente & 32,7 \\
Eran más amplios los espacios y las viviendas & 17,4 \\
La gente era más buena/amable/amistosa/unidos/solidarios & 14,6 \\
Esperaba otra vida y no fue así & 10,6 \\
Había menos delincuencia, narcotráfico y drogadicción & 8,2 \\
Recibía más ayuda, era más barata la vida & 4,5 \\
Había más trabajo & 3,9 \\
Estaba más cercano a servicios & 2,7 \\
Por otras razones & 5,2 \\
Total & $\mathbf{1 0 0}$ \\
\hline * Pregunta abierta que fue recodificada &
\end{tabular}

FUENTE ELABORACIÓN PROPIA A PARTIR DE BASE DE DATOS ESTUDIO SOBRE CAMPAMENTOS Y VIVIENDA SOCIAL REALIZADO POR PROURBANA, CENTRO POLÍTICAS PÚBLICAS UC Y OBSERVATORIO SOCIAL, UAH, 2009.

Quienes residen en conjuntos de vivienda social perciben mayores niveles de intranquilidad, los que vinculan a la presencia de actividades delictuales y al consumo y tráfico de drogas. Señalan, además, tener relaciones más conflictivas con sus vecinos. El contraste es marcado con el recuerdo que tienen de unidad y solidaridad de su vida en el campamento.

En cuanto a los temas de seguridad, la diferencia principal de los campamentos con los conjuntos de vivienda social consiste en el mayor control social que existía. Los asentamientos informales más frecuentes en Chile correspondían a ocupaciones ilegales de terreno, o "tomas", por parte de grupos organizados de "pobladores" con apoyo de partidos o movimientos políticos ${ }^{7}$. Los hogares que forman los campamentos se conocen entre sí. Tienen una historia común, a diferencia de los conjuntos de vivienda social donde confluyen cientos o miles de familias que provienen de las más diversas partes.

Es importante destacar que los niveles de satisfacción de quienes habitan las viviendas sociales van disminuyendo con el tiempo. Los arrepentidos de haberse cambiado van aumentando.

Por último, el tipo de vivienda también determina en forma importante la experiencia de barrio y la satisfacción con éste. Mientras un 79,5 por ciento de quienes viven en departamentos (vivienda multifamiliar en edificios, conocidos como blocks) considera que lo peor de su situación residencial es la "droga, delincuencia, inseguridad, vagancia, mal barrio y problemas con vecinos", sólo un 46,7 por ciento de quienes residen en viviendas unifamiliares o cités de vivienda social tienen la misma opinión.

7 En Chile los llamados "loteos brujos" (las "urbanizaciones pirata" de Colombia o los "loteamientos irregulares" de Brasil) son muy poco frecuentes desde hace muchos años, debido principalmente a las masivas políticas de vivienda y los tempranos programas de regularización de tierras. El alto grado de formalización de la propiedad, fundado en un derecho de propiedad estricto y bien protegido, elimina casi por completo la posibilidad de hacer este tipo de negocios ilegales con el suelo. 
GRÁFICO 1 | RMS 2008: jefes de hogar arrepentidos

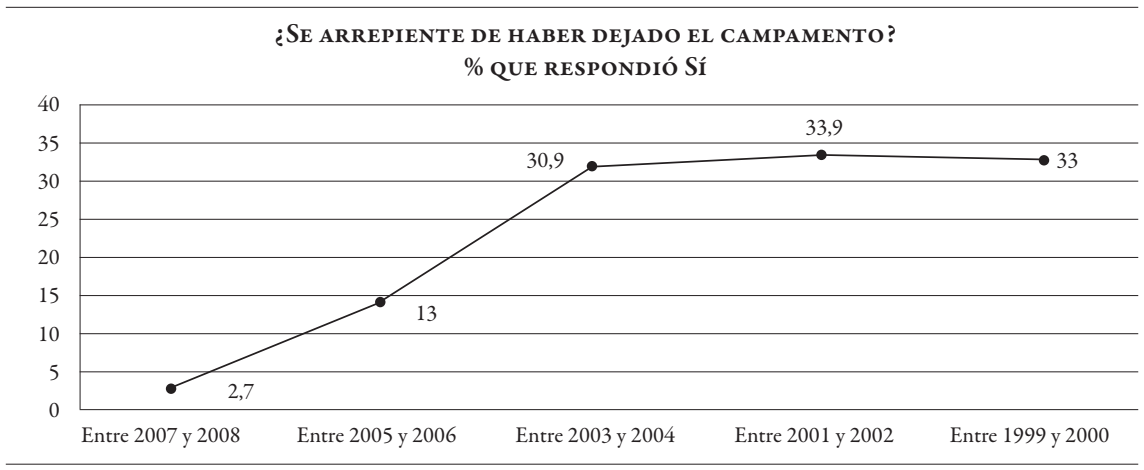

FUENTE ELABORACIÓN PROPIA A PARTIR DE BASE DE DATOS ESTUDIO SOBRE CAMPAMENTOS Y VIVIENDA SOCIAL REALIZADO POR PROURBANA, CENTRO POLÍTICAS PÚBLICAS UC Y OBSERVATORIO SOCIAL, UAH, 2009.

8 De tener la oportunidad, casi la mitad de los que habitan en vivienda social la dejaría

Un número importante de los entrevistados plantea que se iría lo antes posible de su actual vivienda social (46,6 por ciento), mientras que otros tantos optarían por invertir en mejorarla ( 48 por ciento).

CUADRO 14 | RMS 2008: Preferencias residenciales de residentes de vivienda social

\begin{tabular}{lc}
\hline Si USTED TUVIERA UN MEJOR TRABAJO EN EL CUAL GANARA MÁS & \% \\
DINERO, ¿CUÁL DE LAS SIGUIENTES OPCIONES ELEGIRÍA? & 46,6 \\
\hline Se iría lo antes posible de su actual vivienda & 48,0 \\
Invertiría en mejorar su actual vivienda & 1,9 \\
Otra opción & 3,5 \\
NS/NR & $\mathbf{1 0 0 , 0}$ \\
Total
\end{tabular}

* Familias de vivienda social que provienen de campamento

FUENTE ELABORACIÓN PROPIA A PARTIR DE BASE DE DATOS ESTUDIO SOBRE CAMPAMENTOS Y VIVIENDA SOCIAL REALIZADO POR PROURBANA, CENTRO POLÍTICAS PÚBLICAS UC Y OBSERVATORIO SOCIAL, UAH, 2009.

Estas preferencias varían según el tipo de vivienda social. Mientras un 62,6 por ciento de quienes viven en un departamento preferirían irse de su vivienda actual, tan sólo el 24,7 por ciento de quienes habitan en una casa opina igual ${ }^{8}$.

Entre quienes manifiestan querer irse lo antes posible de la vivienda social, un importante 58 por ciento menciona razones relativas al barrio, como que "el barrio es muy peligroso", "hay demasiada delincuencia y droga", "para darle bienestar y seguridad a mis hijos", "porque ya he perdido a mis hijas por la droga" y "no se puede vivir tranquilo". 
9 Los campamentos no son reductos de pobreza "dura", sino una oportunidad para movilizar recursos y estrategias por parte de los hogares más vulnerables

El 60 por ciento de los residentes de campamentos entrevistados habían llegado allí entre los años 2000 y 2008. Este hecho nos sugiere que los asentamientos informales no son reductos de pobreza enclavados en la ciudad. Quienes habitan en ellos no son los hijos de aquellos que en otros tiempos se tomaron un terreno, sino que nuevos hogares que se han mudado allí buscando mejorar sus posibilidades de obtener una vivienda que quede localizada en el sector y comuna que prefieren. En efecto, los jefes de hogar jóvenes (nacidos después de 1970) muestran una mayor movilidad residencial que los jefes de hogar nacidos antes de 1970, a pesar incluso de su más corta edad.

CUADRO 15 | RMS 2008: cambios de vivienda de los jefes de hogares de asentamientos informales, según generación

\begin{tabular}{lcccccc}
\hline NaCidos & UNO & Dos & Tres & CUATro & CinCO O MÁs & TotaL \\
\hline Antes de 1970 & $2,6 \%$ & $17,3 \%$ & $41,2 \%$ & $27,3 \%$ & $11,6 \%$ & $100 \%$ \\
Después de 1970 & $2,9 \%$ & $10,6 \%$ & $34,8 \%$ & $39,3 \%$ & $12,4 \%$ & $100 \%$ \\
Total & $\mathbf{2 , 8 \%}$ & $\mathbf{1 3 , 0 \%}$ & $\mathbf{3 7 , 1 \%}$ & $\mathbf{3 5 , 0 \%}$ & $\mathbf{1 2 , 1 \%}$ & $\mathbf{1 0 0 \%}$ \\
\hline
\end{tabular}

FUENTE ELABORACIÓN PROPIA A PARTIR DE BASE DE DATOS ESTUDIO SOBRE CAMPAMENTOS Y VIVIENDA SOCIAL REALIZADO POR PROURBANA, CENTRO POLÍTICAS PÚBLICAS UC Y OBSERVATORIO SOCIAL, UAH, 2009.

Las trayectorias residenciales de los hogares de campamentos nos muestran que la búsqueda de una mejor geografía de oportunidad es una constante. Tanto las generaciones mayores como las más jóvenes han tendido a buscar una localización más central o urbana en cada una de las etapas de su vida. Al nacer, una proporción significativa tanto de los jefes de hogar mayores como los jefes de hogar jóvenes vivían fuera de la RMS (48 y 34 por ciento, respectivamente).

CUADRO 16 | RMS 2008: Migración comunal y regional de los jefes de hogar antes de llegar al campamento (nacidos antes de 1970)

\begin{tabular}{rccccc}
\hline & $\begin{array}{c}\text { DENTRO DE LA } \\
\text { MISMA COMUNA }\end{array}$ & $\begin{array}{c}\text { DENTRO } \\
\text { DE LA R.M. }\end{array}$ & $\begin{array}{c}\text { OTRA } \\
\text { REgión }\end{array}$ & Ns/NR & \\
\hline Al NACER & $18,6 \%$ & $32,1 \%$ & $48,5 \%$ & $0,8 \%$ & $100,0 \%$ \\
AL DEJAR CADA DE LOS PADRES & $35,1 \%$ & $47,3 \%$ & $16,4 \%$ & $1,2 \%$ & $100,0 \%$ \\
ANTES DE LLEGAR AL & $48,9 \%$ & $29,7 \%$ & $1,6 \%$ & $19,8 \%$ & $100,0 \%$ \\
CAMPAMENTO & & & & & \\
\hline
\end{tabular}

FUENTE ELABORACIÓN PROPIA A PARTIR DE BASE DE DATOS ESTUDIO SOBRE CAMPAMENTOS Y VIVIENDA SOCIAL REALIZADO POR PROURBANA, CENTRO POLÍTICAS PÚBLICAS UC Y OBSERVATORIO SOCIAL, UAH, 2009.

CUADRO 17 | RMS 2008: Migración comunal y regional de los jefes de hogar antes de llegar al campamento (nacidos después de 1970)

\begin{tabular}{rccccc}
\hline & $\begin{array}{c}\text { Dentro De la } \\
\text { Misma COMUNA }\end{array}$ & $\begin{array}{c}\text { Dentro } \\
\text { DE LA R.M. }\end{array}$ & $\begin{array}{c}\text { Otra } \\
\text { Región }\end{array}$ & Ns/NR \\
\hline Al NACER & $29,6 \%$ & $35,0 \%$ & $33,7 \%$ & $1,7 \%$ & $100,0 \%$ \\
Al DEJAR CADA DE LOS PADRES & $47,3 \%$ & $42,3 \%$ & $8,5 \%$ & $1,9 \%$ & $100,0 \%$ \\
ANTES DE LLEGAR AL & $43,0 \%$ & $20,2 \%$ & $1,2 \%$ & $35,6 \%$ & $100,0 \%$ \\
CAMPAMENTO & & & & & \\
\hline
\end{tabular}

FUENTE ELABORACIÓN PROPIA A PARTIR DE BASE DE DATOS ESTUDIO SOBRE CAMPAMENTOS Y VIVIENDA SOCIAL REALIZADO POR PROURBANA, CENTRO POLÍTICAS PÚBLICAS UC Y OBSERVATORIO SOCIAL, UAH, 2009. 
FIGURA 2 | RMS 2008: trayectoria residencial de los jefes de hogar nacidos antes de 1970

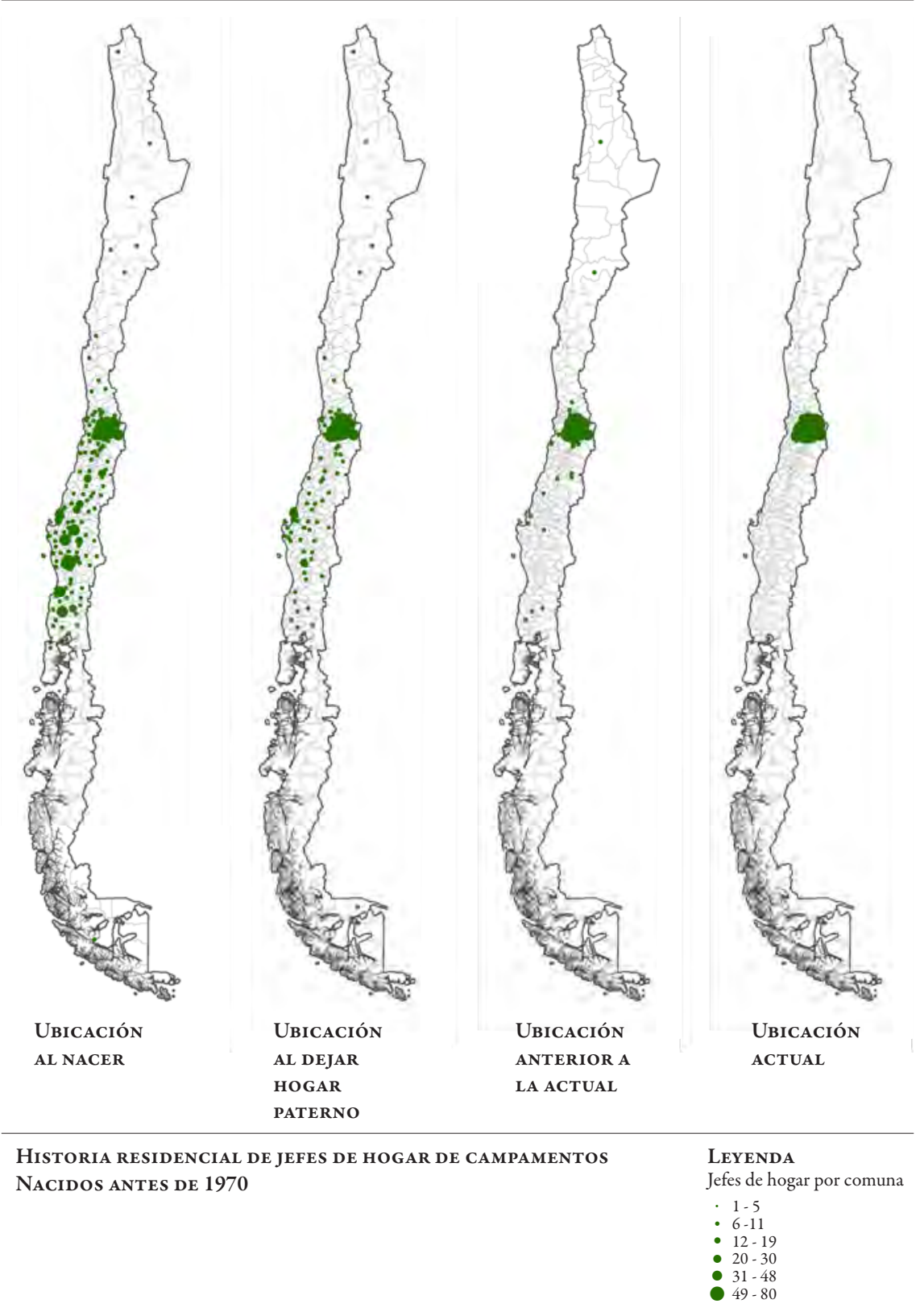

FUENTE ELABORACIÓN PROPIA A PARTIR DE BASE DE DATOS ESTUDIO SOBRE CAMPAMENTOS Y VIVIENDA SOCIAL REALIZADO POR PROURBANA, CENTRO POLÍTICAS PÚBLICAS UC Y OBSERVATORIO SOCIAL, UAH, 2009. 
FIGURA 3 | RMS 2008: Trayectoria residencial de los jefes de hogar nacidos después de 1970

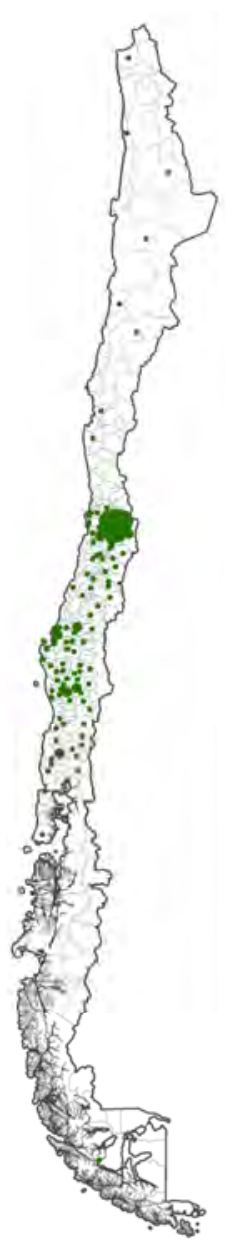

UBicación AL NACER

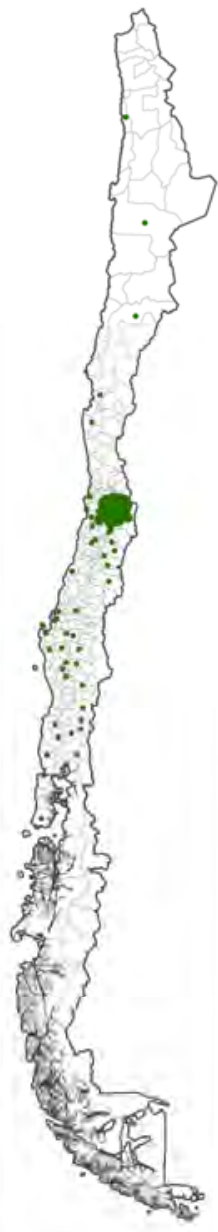

UBICACIÓN AL DEJAR HOGAR PATERNO

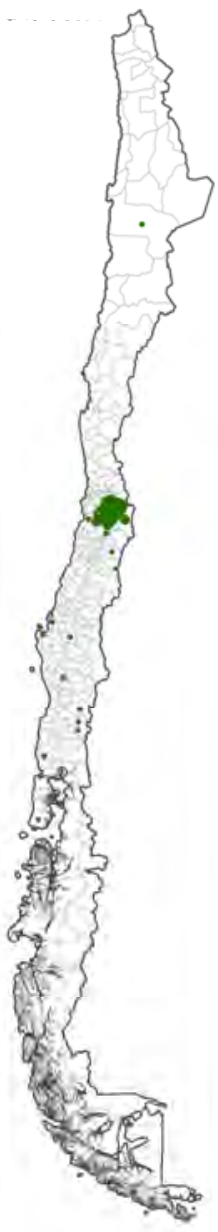

UBICACIÓN ANTERIOR A LA ACTUAL

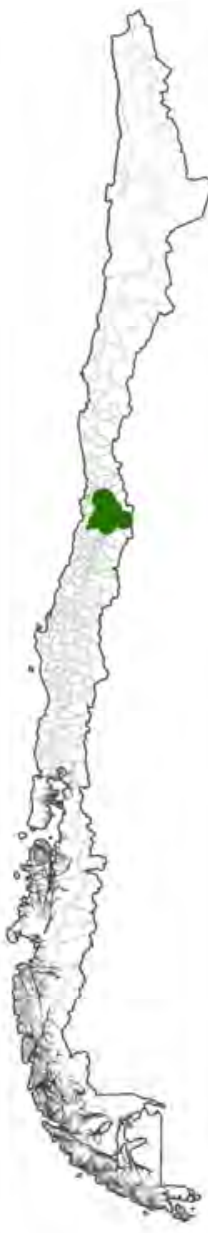

UBICACIÓN ACTUAL

Historia RESIDENCIAL DE JEFES DE HOGAR DE CAMPAMENTOS NACIDOS DESPUÉS DE 1970

LEYENDA

Jefes de hogar por comuna

- $1-5$

- 6-11

- 12 - 19

- $20-30$

- 31 - 48

FUENTE ELABORACIÓN PROPIA A PARTIR DE BASE DE DATOS ESTUDIO SOBRE CAMPAMENTOS Y VIVIENDA SOCIAL REALIZADO POR PROURBANA, CENTRO POLÍTICAS PÚBLICAS UC Y OBSERVATORIO SOCIAL, UAH, 2009.

Por otra parte, si analizamos la ubicación de los campamentos en el país, se advierte que la mayoría de ellos, equivalente a un 73 por ciento, se encuentran al 
interior o cercanos a las ciudades más grandes y pobladas del país. El Catastro de Campamentos 2007 de la Fundación Un Techo para Chile muestra una clara concentración espacial de campamentos y de residentes en campamentos en las tres mayores ciudades de Chile: Santiago (122 campamentos), Concepción (70 campamentos) y Valparaíso (55 campamentos).

Aun más, la mayoría de estos asentamientos están cercanos a servicios, como establecimientos de salud o de educación, o en áreas de fácil acceso al trasporte público, lo que consiguen muchas veces ocupando lugares de alto riesgo, como riberas de ríos, basurales, quebradas y orillas de carreteras. Estos espacios intersticiales son de los pocos deshabitados que van quedando en las ciudades (Brain y Sabatini, 2006).

Un predictor importante de la decisión de localización de los residentes de campamentos es el lugar en que se vivía antes de llegar al campamento. Un número importante de los jefes de hogar de campamentos vivía en la misma comuna, ya sea como allegado o como arrendatario de una casa, departamento o pieza.

CUADRO 18 | RMS 2008: tipo de ocupación de la vivienda de los jefes de hogar antes de llegar al campamento

\begin{tabular}{rccccc}
\hline & Asentamiento informal & Allegado & Arrendaba & Otro & Ns/Nr \\
\hline $\begin{array}{r}\text { Nacidos ANTES } \\
\text { DE 1970 }\end{array}$ & $19,4 \%$ & $55,3 \%$ & $24,4 \%$ & $0,9 \%$ & $100,0 \%$ \\
$\begin{array}{r}\text { NaCido DESPUÉS } \\
\text { DE 1970 }\end{array}$ & $15,5 \%$ & $51,7 \%$ & $30,4 \%$ & $2,2 \%$ & $99,8 \%$ \\
\hline
\end{tabular}

FUENTE ELABORACIÓN PROPIA A PARTIR DE BASE DE DATOS ESTUDIO SOBRE CAMPAMENTOS Y VIVIENDA SOCIAL REALIZADO POR PROURBANA, CENTRO POLÍTICAS PÚBLICAS UC Y OBSERVATORIO SOCIAL, UAH, 2009.

\section{Los asentamientos informales son una realidad urbana y no rural}

Antes de mudarse a su actual vivienda, los jefes de hogar de campamentos de la RMS residían como allegados o arrendatarios de cuartos en comunas con precios de suelo medio-alto y alto, según nuestra clasificación (Figura 4).

Los campamentos se revelan así como una realidad urbana y no rural. Su origen como asentamientos está vinculado con la preferencia ejercida por personas y hogares de extracción popular de residir en barrios y sectores de la ciudad que les ofrecen mejores oportunidades. En las comunas con ingresos más altos se concentran las fuentes de empleo, servicios de salud y educación de mayor calidad, servicios comerciales y equipamiento urbano de un mejor estándar.

La hipótesis que defendemos en estas páginas es, justamente, que a la motivación tradicional para residir en un campamento (poder acceder a la "casa propia") se ha agregado la de mejorar la geografía de oportunidad. La mayor vulnerabilidad social derivada de regímenes laborales flexibles, la pérdida de centralidad política de los "pobladores" y la estigmatización de más y más barrios como "malos" o "críticos", estarían entre los factores que han vuelto la localización en las grandes ciudades una cuestión clave para los grupos populares. 
FIGURA 4 | RMS 2008: localización previa al campamento de los jefes de hogar de campamentos nacidos después de 1970, según precios de suelo

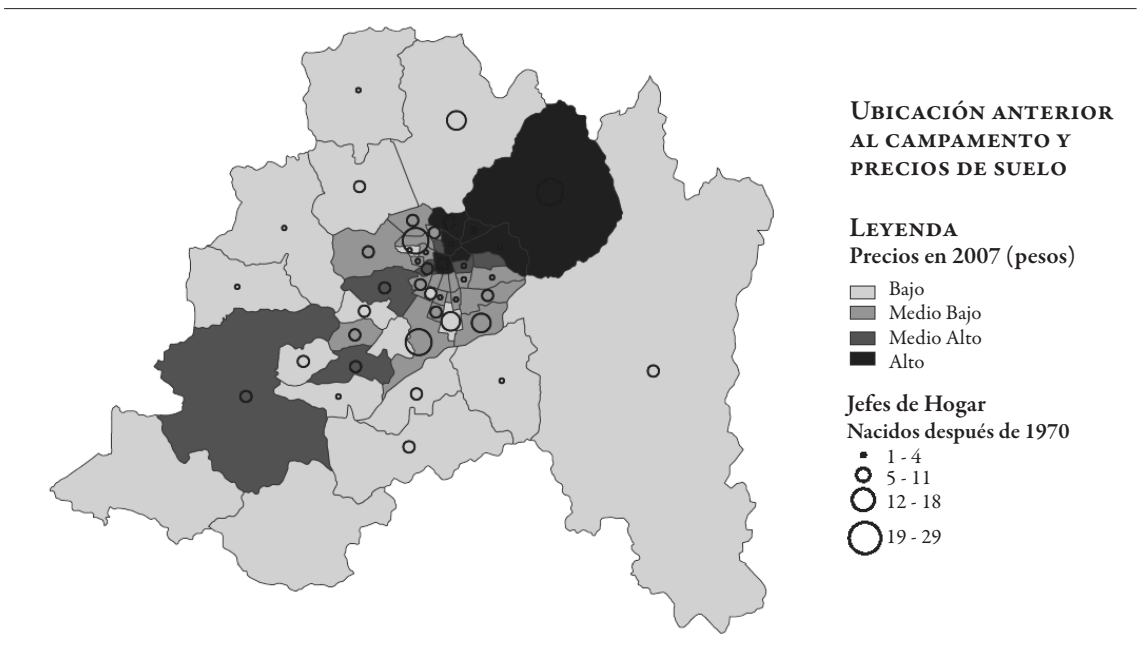

FUENTE ELABORACIÓN PROPIA A PARTIR DE BASE DE DATOS ESTUDIO SOBRE CAMPAMENTOS Y VIVIENDA SOCIAL REALIZADO POR PROURBANA, CENTRO POLÍTICAS PÚBLICAS UC Y OBSERVATORIO SOCIAL, UAH, 2009.

$11 \mathrm{La}$ historia residencial de los residentes de campamentos refleja la importancia que tiene la localización para ellos

Vimos antes que dos tercios de quienes viven en campamentos tienen la expectativa de estar viviendo en una vivienda social en el mismo sitio, sector o comuna antes de cinco años. Vimos también que el 89 por ciento de ellos está postulando o quiere postular a un subsidio de vivienda, los que se desagregan básicamente entre los que pretenden un subsidio para construir en un sitio propio una nueva vivienda (36 por ciento) y los que aspiran a un subsidio para la compra de una vivienda de segunda mano ( 42 por ciento). Ambos tipos de Subsidio Habitacional son relativamente nuevos y buscan apoyar la construcción de una nueva vivienda en el sitio de residencia actual, o bien, la compra de una vivienda usada en una localización preferida.

Lo que estos datos nos indican es que el traslado a un campamento, ciertamente para escapar de la condición de allegado y debido a problemas económicos fuertes, no se hace a cualquier campamento. Se escoge una cierta localización, quedando para más adelante la obtención de un subsidio de vivienda que les facilite quedarse en el lugar -sitio o comuna- por la cual se optó.

La historia residencial de los hogares nos muestra en forma agregada el movimiento centrífugo descrito al comienzo de este artículo. Las familias toman decisiones residenciales que los acerquen los más posible a los lugares o área internas en que existe una mejor geografía de oportunidad, entendiendo que aquéllas están desigualmente distribuidas en la ciudad.

Como veíamos, un 36 por ciento de residentes de campamentos quisiera obtener un subsidio para construir una vivienda nueva en su actual residencia (sitio). Sin em- 
bargo, sabemos que esta posibilidad es muy difícil, puesto que la mayor parte de los campamentos corresponde a ocupaciones irregulares de suelo. El propietario tiene el poder legal de evitar que las familias se radiquen allí o, cuando se trata de los sitios intersticiales que mencionábamos (cuencas de ríos, bordes de carretera, basurales o quebradas), no es posible su radicación por el riesgo o los costos involucrados.

Otro 42 por ciento prefería optar por el subsidio a la vivienda usada. Es una alternativa especialmente idónea para satisfacer las preferencias de estas personas, ya que les amplía el campo de alternativas posibles. La oferta disponible de vivienda para aplicar estos subsidios no queda circunscrita a la periferia lejana de la ciudad, como ocurre abrumadoramente con la vivienda social nueva.

Tres razones usualmente mencionadas para apoyar el desarrollo de un mercado secundario de vivienda social son: (i) que permite una mayor movilidad social de aquellos que se encuentran en condiciones de mejorar su situación, lo mismo que ajustarse a cambios en su composición familiar (aumento o disminución de integrantes del hogar); (ii) que contribuye a frenar la segregación espacial generada con la construcción de vivienda nueva en la periferia urbana, en la medida que absorbe la demanda dentro del stock existente de vivienda social, y (iii) que las preferencias de los compradores de vivienda usada encuentran más espacio, especialmente la posibilidad de elegir su localización.

Los resultados de un estudio sobre el mercado secundario de vivienda social en Santiago realizado por ProUrbana y Lincoln Institute of Land Policy en 2005, respaldan estos argumentos (Brain, Sabatini y lacobelli, 2005).

Aquellas familias que vendían su vivienda social se encontraban en mejor situación económica que aquellas que compraban una vivienda usada, mostrando una tendencia a la movilidad social ascendente. Mientras las primeras tenían un ingreso per cápita anual de US\$ 1.290 en promedio, las compradoras uno de US\$ 1.000 en promedio.

Por otra parte, el estudio respaldaba nuestra tesis sobre la importancia creciente del factor localización en las preferencias y necesidades habitacionales de los grupos populares urbanos. Las decisiones de compra y precios pagados por los adquirentes de vivienda social usada, mostraban una disposición a transar 7,5 metros cuadrados de vivienda por cada kilómetro más cerca del Centro de Santiago (Brain, Sabatini y lacobelli, 2005).

12 ¿Qué posibilidades reales de elegir la localización entrega a las familias de campamentos el subsidio a la vivienda usada?

La oferta de vivienda usada susceptible de ser comprada con el nuevo subsidio está localizada en distritos más centrales y consolidados de la RMS que las viviendas sociales nuevas. Estudiamos la oferta de vivienda con precios entre 16 y 40 mil dólares el segundo semestre del año 2007 en la RMS, y llegamos a esa conclusión. Las más baratas podían ser financiadas en su totalidad con el subsidio de vivienda, mientras que las más caras, parcialmente 9

9 Estos datos corresponden a información recolectada por ProUrbana el segundo semestre del año 2007 a partir de: (i) información de oferta habitacional (www.portalinmobilario.cl, www.elinmobiliario.cl); (ii) transacciones de vivienda con subsidio D.S. $N^{\circ} 40$ en el 2006 (base Minvu); (iii) análisis oferta de subsidios habitacionales (Minvu), y (iv) levantamiento de ofertas de créditos hipotecarios de bancos (Falabella, Ripley, Banefe, Banco del Estado y Banco del Desarrollo). 
En la Figura 5 se aprecia esa diferente localización de viviendas sociales nuevas y usadas de tipo unifamiliar (casas). Las casas usadas muestran otras ventajas fuera de su localización, como es su mayor tamaño y menor precio. Tenían, en promedio, un tamaño de $67 \mathrm{~m}^{2}$ y un precio de US\$32.240; mientras que las casas nuevas, sólo $48 \mathrm{~m}^{2}$ y un precio de US\$33.160.

La oferta de departamentos usados se distribuye en un mayor número de comunas que los departamentos nuevos (Figura 6). El subsidio de Renovación Urbana ha ayudado a concentrar estos últimos en las áreas centrales. En lo demás, la oferta de departamentos económicos de segunda mano se comporta en forma similar que las casas usadas. En promedio su superficie es de $55 \mathrm{~m}^{2}$ y su valor promedio es de US\$26.945, mientras que los departamentos nuevos tienen un tamaño promedio bastante menor $\left(38 \mathrm{~m}^{2}\right)$ y un valor promedio mayor de US\$30.836.

Del análisis de la oferta de viviendas económicas podemos concluir que efectivamente las viviendas usadas, independiente de si son departamentos o casas, se encuentran mejor localizadas que las viviendas nuevas, además de presentar claras ventajas en cuanto a su tamaño y valor. En este sentido, permitirían a las familias que optan por un subsidio a la vivienda usada elegir entre más alternativas.

FIGURA 5 | RMS, segundo semestre de 2007: Oferta de Casas Nuevas y Usadas con precios entre 400 y $1.000 \mathrm{UF}$

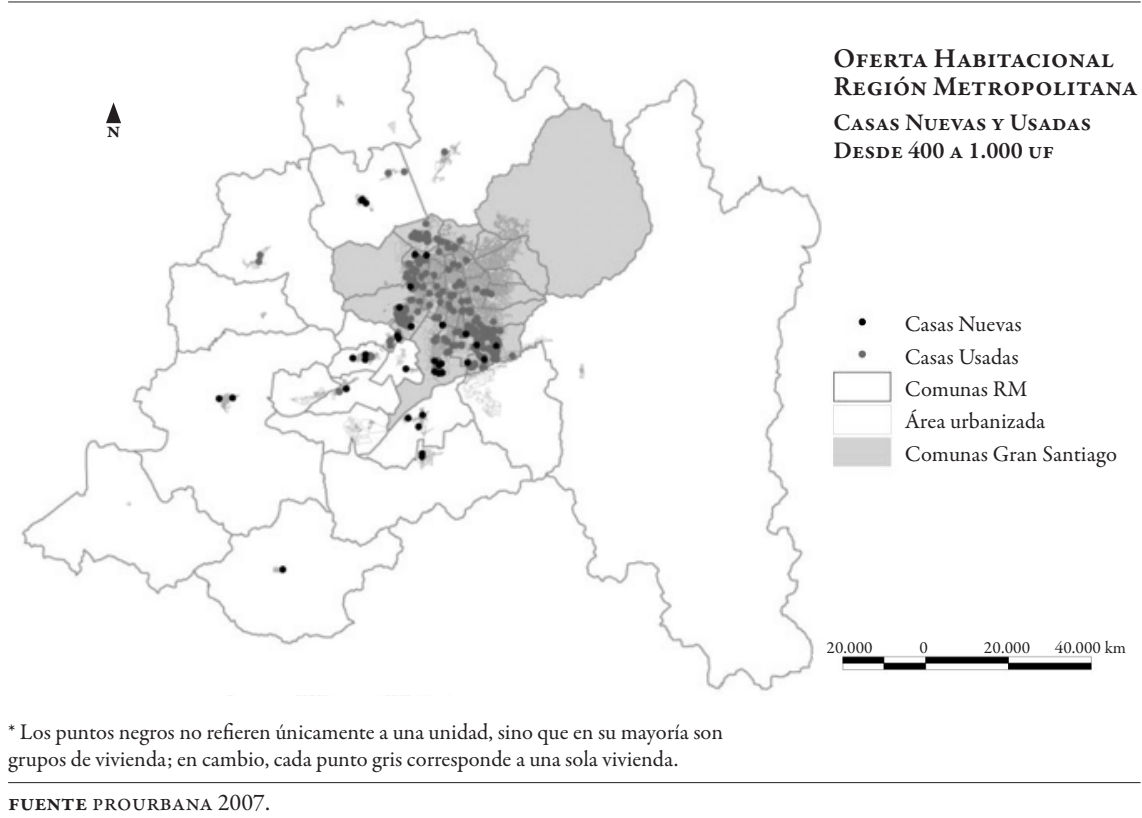


FIgURA 6 | RMS, segundo semestre de 2007: Oferta de Departamentos Nuevos y Usados con precios entre 400 y $1.000 \mathrm{UF}$

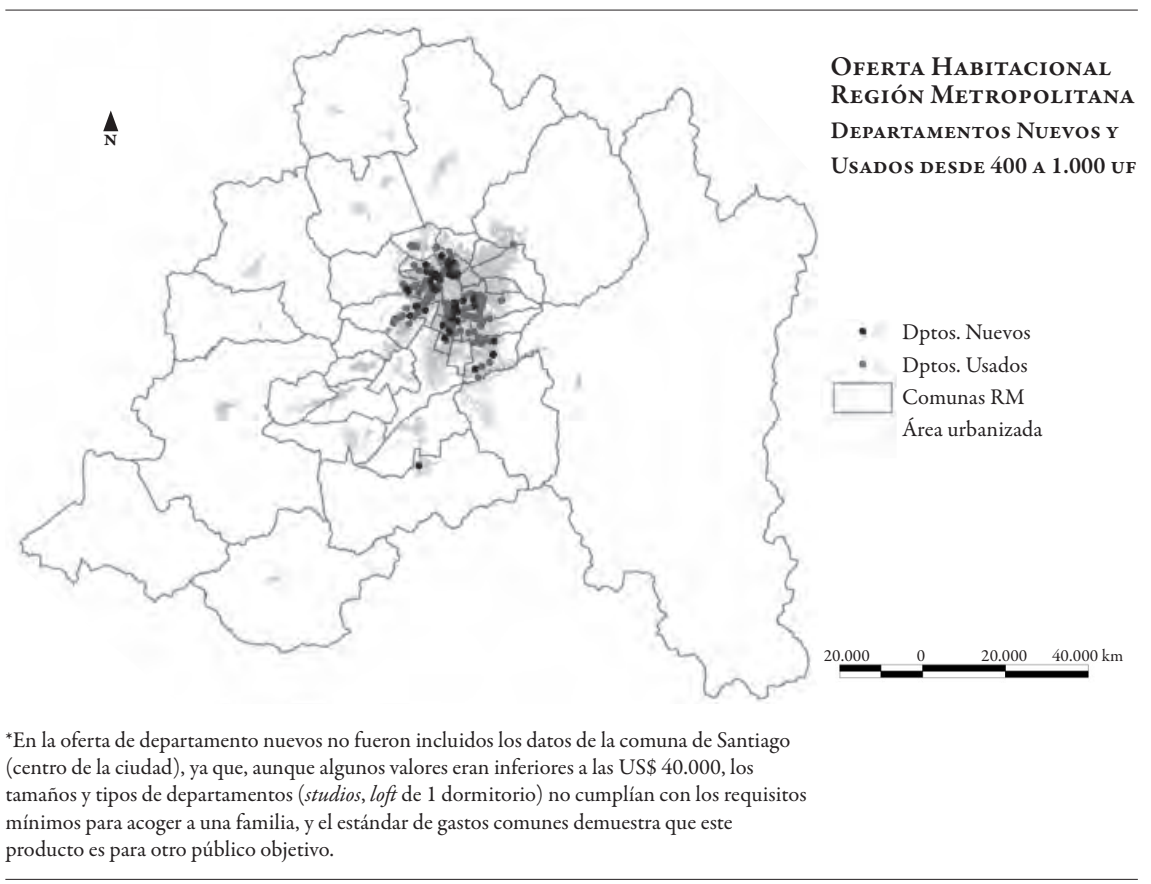

FUENTE PROURBANA 2007.

\section{Conclusiones y consideraciones finales}

Vivir en un campamento aumenta la probabilidad, no sólo de obtener una vivienda social en un menor período de tiempo, sino también de ejercer las preferencias de localización. Vivir en un campamento es la mejor estrategia para alcanzar ambos objetivos; la mejor forma de escapar del trade off que enfrenta la mayoría de hogares de extracción popular entre una buena localización, como la que provee el arriendo de una vivienda de tugurio en distritos centrales, y acceder en propiedad a una vivienda formal, como la que se consigue en la periferia segregada y mal servida a través de los programas de vivienda social.

Los hogares de Santiago que están siguiendo esta estrategia tienen un perfil distinto que aquellos en situación de pobreza. En los campamentos predominan los hogares con jefatura masculina y con ingresos que, siendo bajos, están por encima de la línea oficial de la pobreza. Vivir en un campamento resulta atractivo porque favorece la cercanía a las oportunidades de trabajo, tanto para el jefe de hogar como para su cónyuge; y también porque, como barrios, los campamentos están menos cruzados por la violencia y el crimen que muchos conjuntos de vivienda social.

Las políticas de vivienda de los gobiernos chilenos han estado siempre alineadas en la noción de "déficit habitacional". Los hogares son números que producen una lista de espera que será gestionada administrativamente. Cada hogar obtiene 
un Subsidio Habitacional en forma independiente, sin considerar aspectos como mantención de redes sociales y preferencias de localización, que son también dimensiones importantes del "problema de la vivienda".

Creado en 1996, el programa Chile-Barrio -hoy LAC- representa una excepción. Teniendo por objetivo solucionar el problema de vivienda de las familias de campamentos, ha trabajado con un enfoque territorial. Su "unidad de intervención" ha sido el campamento y no el hogar. Los resultados de nuestro estudio indican que este criterio de focalización rinde mejores frutos que el criterio tradicional de focalización en el hogar.

En suma, una política habitacional exitosa, considerando la gran cantidad de viviendas producidas y la reducción de los asentamientos informales, presenta un divorcio creciente entre lo que ofrece y las necesidades específicas de los hogares socialmente vulnerables. Éstos no sólo requieren una vivienda en cuanto infraestructura básica mínima, sino que una buena localización. Importan cada vez más la seguridad y tranquilidad del barrio, el fortalecimiento de las redes sociales y la "geografía de oportunidad", especialmente el acceso a las oportunidades laborales.

La política de vivienda actual, basada en un subsidio a la demanda y sujeta a los mercados de suelo, ha generado segregación a gran escala de los grupos populares en la periferia urbana; y nuestro estudio empírico nos muestra que existen, en relación con ello, resistencias y estrategias para modificar este resultado por parte de las familias. No da lo mismo el lugar en que se localiza la vivienda. Ese es nuestro hallazgo principal. Tanto es así, que hay familias dispuestas a vivir en campamentos con fin de lograr ejercer sus preferencias de localización, a pesar de la precariedad física, menoscabo social e inseguridad jurídica que ello comporta.

No es la vivienda misma la fuente de descontento, sino que la experiencia de gueto que se vive en los conjuntos de vivienda social. Por una parte, los residentes de campamentos evalúan en forma positiva la vivienda social, y en eso no difieren de otros grupos de extracción popular y, por otra, los residentes de vivienda social rememoran con dejos de nostalgia su anterior vida en el campamento.

Razones de la buena evaluación de la vivienda social por parte de quienes viven en campamentos hay varias. Una, es que son precisamente esos hogares los que ejercen mejor sus preferencias. Como vimos antes, gran parte de quienes hoy están en viviendas sociales y provienen de campamentos, viven en la misma comuna en que estaba el campamento. Otra razón es que, frente a la aguda precariedad habitacional de quienes actualmente residen en campamentos, lo que ofrece la política habitacional a las familias es una mejoría sustantiva respecto a sus condiciones de vida, a saber, una vivienda sólida, con baño y cocina al interior de la casa, sistema eléctrico y de alcantarillado regularizado. Hay que considerar también que la vivienda se entrega en propiedad y no conlleva el pago de dividendos ${ }^{10}$.

La resistencia de los hogares de campamentos a vivir en forma segregada se ha ido acrecentando en los últimos tiempos. El problema no es tanto la lejanía a ser-

10 El subsidio de vivienda para las familias más pobres se entrega en propiedad, y las familias para obtener el subsidio deben ahorrar solo el $3 \%$ del valor de la vivienda ( 400 dólares aprox.). 
vicios -la cobertura social en educación y salud en Chile es cercana al ciento por ciento- sino, más bien, la homogeneidad social a gran escala y los problemas sociales que la acompañan. Son espacios residenciales en que sus residentes tienen que recorrer kilómetros para encontrarse con alguien de otra condición social. Anidan dinámicas sociales perversas que reconocemos en la noción de guetización: consumo de drogas, deserción escolar, embarazo adolescente, crimen, narcotráfico y violencia. No pocos de quienes viven en estos conjuntos de vivienda social atesoran sueños de irse a barrios mejores, tranquilos, incluso al campo, donde sus hijos no corran peligro ni reciban malas influencias.

Siempre ha sido importante en Chile el debate en torno a la cantidad de viviendas que se deben construir para terminar con el déficit habitacional. También ha habido una preocupación por su calidad; y en los últimos años se ha incorporado a la discusión pública el objetivo de integración social al que deberían contribuir las políticas de vivienda social.

En rigor, el de integración social ha sido siempre un objetivo de las políticas habitacionales chilenas, como lo ha sido la reactivación de la economía nacional, especialmente en períodos de recesión. El acceso a la vivienda propia ha sido un vehículo portentoso de integración social para los hogares de extracción popular.

Lo que es nuevo es la inquietud por hacer frente a los graves problemas sociales que la vivienda social está produciendo bajo la nueva economía y que se relacionan con su localización segregada, problemas que se resumen en la idea de guetización de los barrios populares. Sin embargo, las autoridades han circunscrito su entendimiento de los desafíos de integración social a la cercanía a servicios y equipamientos, soslayando la importancia que tiene la diversidad social de los barrios. La integración social corresponde tanto a una como a la otra dimensión. De hecho, hay que diferenciar la falta de acceso físico a servicios y equipamientos urbanos de la falta de contacto social por encima de las fronteras de clase. La primera es importante en la medida en que la segregación espacial en la ciudad vuelve más pobres a los pobres. Pero la segunda es la que estimula los procesos de desintegración social o guetización de los barrios populares. "No hay contrato social sin contacto social", señalan acertadamente Blakely y Zinder en su descripción de las nuevas formas de segregación residencial en las ciudades de los Estados Unidos (1997).

Los nuevos hogares que se instalan en los campamentos despliegan, entonces, una estrategia residencial para ejercer un mayor control espacial de su situación residencial. Resisten la salida hacia la periferia que afecta a los hogares populares que acceden a una vivienda social. Buscan permanecer donde están, ya sea por medio de una radicación en el mismo sitio o bien yéndose a una vivienda en la misma comuna. IEURE 


\section{Referencias bibliográficas}

Alonso, W. (1964). Location and Land Use. Harvard: Harvard University Press.

Blakely, E. \& M. Snyder (1997). Fortress America. Gated Communities in the United States. Washington, DC: Brookings Institution Press \& Lincoln Institute of Land Policy.

Brain, I., Sabatini, F. \& lacobelli, A. (2005). Calidad y valor de la vivienda social: un problema de localización y barrio. Revista ProUrbana \#2.

Brain, I. \& Sabatini, F. (2006). Oportunidades, Equidad y Ciudad: Los nuevos pobladores. Documento \#7. Santiago: Centro de Investigación Social, Fundación Un Techo para Chile.

Concha, M., del Campo, P. \& Brain, I. (2003). Situación post-erradicación de las familias de campamentos. Santiago: Centro de Investigación Social, Fundación Un Techo para Chile. En www. untechoparachile.cl/cis

Faletto, E. (1964). Incorporación de los Sectores Obreros al Proceso de Desarrollo. Santiago: Instituto Latinoamericano de Planificación Económico Social.

Fundación Un techo para Chile (2007). Catastro de Campamentos 2007. En www.untechoparachile.cl/cis

Galster, G. \& Killen, S. (1995). The geography of opportunity: A reconnaissance and conceptual framework. Housing Policy Debate, 6, 1, 7-43.

Harvey, D. (1974). Social Justice and the City. Baltimore: Johns Hopkins University Press.

INVI, Instituto de la Vivienda de la Universidad de Chile (2001). Diagnóstico de medición de satisfacción de beneficiarios de vivienda básica. Santiago: INVI.

MIDEPLAN, Ministerio de Planificación y Cooperación de Chile (2006). Encuesta de Caracterización Socioeconómica Nacional, CASEN, 2006. En www.mideplan.cl

MINVU/INVI (2002). Sistema de medición de beneficiarios de vivienda básica: sintesis del informe de consultoría. Santiago: FAU-UCH y División Técnica de Estudio y Fomento Habitacional del MINVU.

Morse, R. (1971). La Investigación Urbana Latinoamericana: Tendencias y Planteos. Buenos Aires: Nueva visión.

Rodríguez, A. \& Sygranyes, A. (2000). Necesidades de una política de vivienda y de ciudad: Ampliar el campo de acción y mantener el patrimonio construido. Revista Ambiente y Desarrollo. Vol. XVI - No 3 (ISSN 0716 - 1476).

Sabatini, F. \& Cáceres, G. (2004). Los barrios cerrados y la ruptura del patrón tradicional de segregación en las ciudades latinoamericanas: el caso de Santiago de Chile. En G. Cáceres \& F. Sabatini (Eds.). Los Barrios Cerrados en Santiago de Chile: Entre la Exclusión y la Integración Social. Santiago: Instituto de Geografía, PUC Chile.

Sabatini, F., Cáceres, G. \& Cerda, J. (2001). Segregación residencial en las principales ciudades chilenas: Tendencias de las tres últimas décadas y posibles cursos de acción. Revista EURE, $27(82)$.

Sabatini, F., Wormald, G., Sierralta, C. \& Peters, P. (2009). Residential segregation in Santiago: scalerelated effects and trends, 1992-2002. En B. Roberts \& R. Wilson (Eds.). Urban Spatial Differentiation and Governance in the Americas. USA: Palgrave-Macmillan.

Skewes, J.C. (2003). Casa nueva, ¿̇ida nueva?: el paradójico amanecer en las villas. Documento \#2. Santiago: Centro de Investigación Social, Fundación Un Techo para Chile.

Touraine, A. (1987). La Centralidad de los Marginales. Proposiciones $N^{\circ} 14$. Santiago de Chile: SUR. 
Wormald, G. (2007). ¿Cómo debe entenderse la integración social en la ciudad? Santiago: Publicación del Ciclo de Reuniones del Consejo Directivo de ProUrbana, Políticas Públicas UC. www. prourbana.cl 